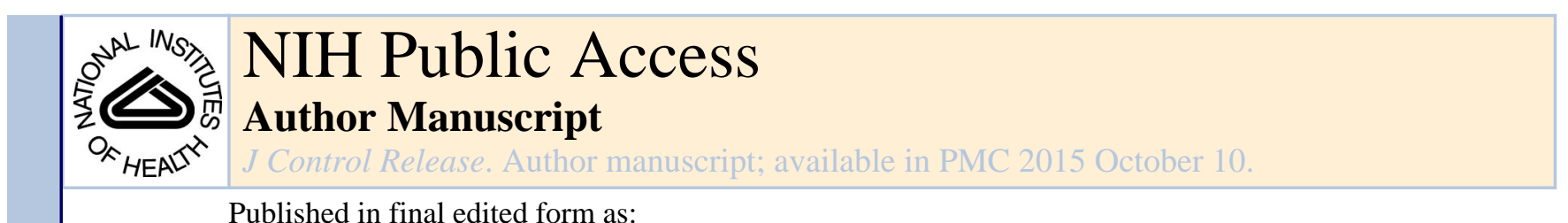

Published in final edited form as:

J Control Release. 2014 October 10; 191: 34-46. doi:10.1016/j.jconrel.2014.05.044.

\title{
Pluronic modified leptin with increased systemic circulation, brain uptake and efficacy for treatment of obesity ${ }^{\star}$
}

\author{
Xiang Yia, ${ }^{a}$, Dongfen Yuan ${ }^{a}$, Susan A. Farr ${ }^{b}$, William A. Banks ${ }^{c, d}$, Chi-Duen Poon ${ }^{e}$, and \\ Alexander V. Kabanova,f,* \\ a Center for Nanotechnology in Drug Delivery and Division of Molecular Pharmaceutics, \\ Eshelman School of Pharmacy, University of North Carolina at Chapel Hill, Chapel Hill, NC \\ 27599, USA \\ b Research and Development, VA Medical Center and Division of Geriatrics, St. Louis University \\ School of Medicine, St. Louis, MI, USA \\ ${ }^{c}$ Geriatric Research, Education, and Clinical Center, Veterans Affairs Puget Sound Health Care \\ System, Seattle, WA 98108, USA \\ d Division of Gerontology and Geriatric Medicine, Department of Medicine, University of \\ Washington School of Medicine, Seattle, WA 98108, USA \\ e Research Computer Center, University of North Carolina at Chapel Hill, Chapel Hill, NC 27599, \\ USA
}

${ }^{f}$ Faculty of Chemistry, M.V. Lomonosov Moscow State University, 119899 Moscow, Russia

\section{Abstract}

\begin{abstract}
Modification of hydrophilic proteins with amphiphilic block copolymers capable of crossing cell membranes is a new strategy to improve protein delivery to the brain. Leptin, a candidate for the treatment of epidemic obesity, has failed in part because of impairment in its transport across the blood-brain barrier (BBB) that develops with obesity. We posit that modification of leptin with poly(ethylene oxide)- $b$-poly(propylene oxide)- $b$-poly (ethylene oxide), Pluronic P85 (P85) might permit this protein to penetrate the BBB independently of its transporter, thereby overcoming peripheral leptin resistance. Here we report that peripherally administered leptin-P85 conjugates exhibit biological activity by reducing food intake in mouse models of obesity (ob/ob, and dietinduced obese mouse). We further generated two new leptin-P85 conjugates: one, Lep(ss)P85(L), containing one P85 chain and another, Lep(ss)-P85(H), containing multiple P85 chains. We report data on their purification, analytical characterization, peripheral and brain pharmacokinetics (PK). Lep(ss)-P85(L) crosses the BBB using the leptin transporter, and exhibits
\end{abstract}

\footnotetext{
${ }^{2}$ The work was carried out in parts: Center for Drug Delivery and Nanomedicine, at Nebraska Medical Center, Omaha, NE, UNC Eshelman School of Pharmacy, University of North Carolina at Chapel Hill, NC, St. Louis University School of Medicine, St. Louis, MO, and University of Washington School of Medicine, Seattle, WA.

(C) 2014 Elsevier B.V. All rights reserved.

* Corresponding authors at: Center for Nanotechnology in Drug Delivery and Division of Molecular Pharmaceutics, UNC Eshelman School of Pharmacy, University of North Carolina at Chapel Hill, Chapel Hill, NC 27599-7363, USA. Tel.: +1 919962 1010; fax: +1 919962 9922. xiang_yi@unc.edu (X. Yi), kabanov@unc.edu (A.V. Kabanov)..

Appendix A. Supplementary data

Supplementary data to this article can be found online at http://dx. doi.org/10.1016/j.jconrel.2014.05.044.
} 
improved peripheral PK along with increased accumulation in the brain compared to unmodified leptin. Lep(ss)-P85(H) also has improved peripheral PK but in a striking difference to the first conjugate penetrates the BBB independently of the leptin transporter via a non-saturable mechanism. The results demonstrate that leptin analogs can be developed through chemical modification of the native leptin with P85 to overcome leptin resistance at the level of the BBB, thus improving the potential for the treatment of obesity.

\section{Keywords}

Leptin; Pluronic block copolymer; Protein-polymer conjugation; Brain pharmacokinetics; Bloodbrain barrier; Obesity

\section{Introduction}

Leptin is a $16 \mathrm{kDa}$ regulatory protein secreted by fat cells and acting within the brain to control appetite and thermogenesis [1-3]. It crosses the blood-brain barrier (BBB) by a specific, saturable transport system [4]. A decade ago, recombinant leptin was tested unsuccessfully as a therapy for reduction of body weight in obese patients. We now appreciate that the early attempts of leptin monotherapy failed because of leptin resistance manifested in the obese patients. Animal and human studies show that leptin resistance can occur at three levels: reduced transport at the BBB, impaired leptin receptor function in the hypothalamus, and altered response of anorectic/orexigenic downstream neuronal circuitries [5-7]. A great deal of effort has been made to address leptin receptor resistance. For example, a combination of amylin with leptin led to profoundly synergistic reductions in food intake and body weight in the obese patients and diet-induced obese (DIO) mice [8,9]. By activating amylin receptor within the hindbrain area postrema and subsequent polysynaptic connection to the hypothalamus, amylin sensitizes the ventromedial hypothalamus, resulting in the augmentation of leptin-induced phosphorylated signal transducer and activator of transcription (STAT) 3 activation [8]. Leptin resistance at the level of the BBB has also been demonstrated. Indeed, an impaired BBB transport is important in the maintenance and probably in the progression of obesity [7,10-12]. In particular, leptin transporter defects predominate over brain receptor defects early on in outbred models of rodent DIO [7]. Modeling based on cerebrospinal fluid (CSF) and serum levels of leptin indicates that in advanced obesity in humans (leptin levels of about $40 \mathrm{ng} /$ $\mathrm{mL}$ ), transporter defects account for about $2 / 3$ of resistance to peripheral leptin [13]. Thus, just as in the rodent and canine models $[10,14,15]$, it is expected that moderately obese humans with poor response to peripherally administered leptin [16] would still respond better to a leptin that could reach brain receptors.

Several strategies have been explored to improve leptin action by way of peripheral administration route. Modification of leptin with polyethylene glycol (PEG) extended leptin serum circulation [17]. However, subcutaneous administration of PEGylated leptin failed in clinical trials as a weight control drug for obesity treatment $[18,19]$. It is known that PEGylation of proteins sometimes increases and sometimes decreases the permeability of those proteins at the BBB [20-22], but in a specific study a PEGylated leptin was 
completely unable to cross the BBB [23]. Similarly, a genetically engineered Fc-leptin fusion protein had no anti-obesity effect on DIO mice, although it increased serum half-life of leptin and induced more weight loss than leptin in ob/ob mice [24]. To target brain, leptin was also modified with trans-activating transcriptional activator (TAT), a cell-penetrating peptide that is widely explored to facilitate cellular uptake of various molecular cargos. After intravenous (i.v.) injection, the modified leptin was detected in a greater amount than leptin in brain hypothalamus and showed greater response than leptin in inducing weight loss in high-fat diet Balb/c mice $[25,26]$. The most recent attempt in leptin development is a leptin peptide mimics that carries a carbohydrate moiety aiming for active transport across the BBB. Following multiple daily intraperitoneal (i.p.) $(0.5 \mathrm{mg} / \mathrm{kg} /$ day for 11 days) or intranasal $(0.1 \mathrm{mg} / \mathrm{kg} /$ day for 10 days) injections, this leptin peptide controlled body weight gain in DIO mice [27]. The transport rate at the BBB is a key factor underlying the ability of any substance to enter the brain and efforts have been made to improve leptin transporter activity at the BBB. For example, leptin co-administration with epinephrine showed a greater uptake by mouse brain [28]. Altogether, these studies suggest that overcoming transporter resistance at the BBB and increasing delivery of leptin to the brain could significantly improve leptin therapeutic efficacy and increase weight loss. Among the aforementioned delivery strategies, some (e.g. leptin peptide mimics) might move to clinical tests, while others (e.g. TAT modification) might encounter safety concerns. However, the problem remains unresolved. Thus developing a safe, efficacious and translatable approach to overcome peripheral resistance to leptin could address an unmet medical need and result in a therapeutic product for the treatment of obesity.

Toward this goal we proposed to modify leptin with pluronic block co-polymers, aiming to improve the peripheral pharmacokinetics (PK) of leptin and its brain uptake. "Pluronics" or "poloxamers" are amphiphilic triblock copolymes consisting of (poly(ethylene oxide)- $b$ poly (propylene oxide)- $b$-poly(ethylene oxide) (PEO-PPO-PEO, same as poly(polyethylene glycol)- $b$-poly(propylene glycol)- $b$-poly(polyethylene glycol) or PEG-PPG-PEG). We reported on the first generation of the modified product, Lep(ss)-P85, showing an elongated serum half-life time, higher stability in blood and brain, and rapid transport rate across the BBB in a non-saturable and leptin transporter independent manner [29]. The in vivo biological activity of this Lep(ss)-P85 was shown by an acute reduction in food intake in normal body weight mice [29]. In an extension of this approach, we have continuously produced leptin-pluronic conjugates with the goal to improve their purity, PK profile, and efficacy. Herein, we report the new data obtained during this optimization process that involved conjugate production, analytical characterization, peripheral and brain PK analysis and efficacy evaluation in models of obese mice.

\section{Materials and methods}

\subsection{Materials}

Mouse recombinant leptin (Lep) and a chimera leptin receptor (ObRFc) were purchased from R\&D Systems (Minneapolis, MN). 4-Methoxyltrityl chloride (MTr-Cl), 1,1'carbonyldiimidazole (CDI), 1,2-ethylenediamine (EDA), ninhydrin, s-glutathione (reduced), ethylenediaminetetraacetic acid (EDTA), sinapinic acid, trichloroacetic acid (TCA), 
trifluoroacetic acid (TFA), iodoacetamide (IAA), triethylamine, anhydrous acetonitrile, anhydrous pyridine, methanol, dichloromethane, toluene, acetone, ethanol, isopropanol, dimethylformamide (DMF), PEG-SOD1 (S9549), human male AB serum and silica gel (288616, 70- 270 mesh, 60 Å) were purchased from Sigma-Aldrich Co. (St-Louis, MO). Pluronic P85 (P85) (lot no. WPOP-587A, average M.W. 4600) was kindly provided by BASF Corp. (Parispany, NJ). Dithiobis(succinimidyl propionate) (DSP), disuccinimidyl propionate (DSS), dithiothreitol (DTT) and bovine serum albumin (BSA) were from Thermo Fisher Scientific (Rockford, IL). Carboxymethyl dextran chip (CM5), $N$ hydroxysuccinimide (NHS), 1-ethyl-3-(3-dimethylaminopropyl) carbodiimide (EDC), ethanolamine-HCl, HBS-EP buffer (10 mM HEPES, $150 \mathrm{mM} \mathrm{NaCl}, 3$ mM EDTA, 0.005\% surfactant P20, pH 7.4), protein G, Sephadex LH-20 gel and Illustra NAP-10 or 25 columns were from GE Healthcare (Piscataway, NJ). Amicon Ultra $0.5 \mathrm{~mL}$ centrifugal filters ( $10 \mathrm{kDa}$ MWCO) and Amicon Ultra centrifugal filter units Ultra-15 (MWCO $10 \mathrm{kDa}$ ) were from Sigma-Aldrich Co. (St-Louis, MO). FLOAT-A-LYZER G2 (8-10 kDa MWCO) was from Spectrum Laboratories, Inc. (Rancho Dominguez, CA). Flexible thin-layer chromatography (TLC) plates were from Whatman Ltd (Mobile, AL).

\subsection{Synthesis, purification and analysis}

2.2.1. Synthesis of leptin-P85 conjugates-The synthesis was carried out as previously reported [30]. Briefly, $\mathrm{P} 85$ was reacted with $\mathrm{MTr}-\mathrm{Cl}$ (1:1 molar ratio) and purified on Silicagel column $(3 \times 40 \mathrm{~cm})$ with stepwise elution in dichloromethane containing $2 \%, 5 \%$ and $10 \%$ methanol. The resulting mono-MTr-P85 (80\% wt. yield) was activated by excess of CDI, mixed with EDA and finally treated with TFA to remove MTr protection. The resulting monoamine $\mathrm{P} 85$ was further purified using gel-permeation chromatography on Sephadex LH-20 column $(2.5 \times 30 \mathrm{~cm})$ in methanol. The amino groups were assayed qualitatively by TLC and quantitatively by ninhydrin assay. To produce leptin-P85 conjugates, the obtained monoamine P85 was activated by excess of DSP linker followed by elution in Illustra NAP- 25 columns in $20 \%$ aqueous ethanol to remove excess of unreacted linker. Fractions containing activated P85 copolymers were immediately mixed with leptin (molar ratio of leptin to P85 1:10) in $20 \%$ aqueous ethanol supplemented with sodium borate buffer $(0.1 \mathrm{M}, \mathrm{pH} 8.0)$. After incubation overnight at $4{ }^{\circ} \mathrm{C}$, the reaction mixture was precipitated in cold acetone to remove excess of free P85 copolymers, as described previously [30]. The obtained precipitates were then desalted, sterilized and stored for animal feeding study or further purified as described below.

2.2.2. Purification of leptin-P85 conjugates-The above obtained conjugates (Lep(ss)-P85) were subjected to size exclusion chromatography (SEC) on TSKgel G2000SW column $(7.8 \mathrm{~mm} \times 30 \mathrm{~cm}$, Tosoh Bioscience LLC, Grove City, OH) using a Shimadzu HPLC system with a multiple-wavelength UV-detector (Shimadzu Scientific Instruments, Columbia, MD) and eluted in $0.1 \mathrm{M} \mathrm{Na}_{3} \mathrm{PO}_{4} / 0.2 \mathrm{M} \mathrm{NaCl}(\mathrm{pH}$ 7.4) containing $10 \%$ methanol at a flow rate of $1 \mathrm{~mL} / \mathrm{min}$. Protein fractions were collected, desalted using Amicon Ultra centrifuge filter unit and analyzed by electrophoresis and mass spectra. Fractions eluted at $8.8 \mathrm{~min}$ (designated as Lep(ss)-P85(H)) and $9.5 \mathrm{~min}$ (designated as Lep(ss)-P85(L)) were further sterilized and stored for animal pharmacokinetic study. 
2.2.3. MALDI-TOF spectra-Mass values of leptin-P85 conjugates were determined by matrix-assisted laser desorption/ionization time of fly (MALDI-TOF) spectroscopy in 4800 MALDI TOF/TOFTM analyzer (Applied Biosystems/MDS SCIEX) at a laser power of 3000 $\mathrm{V}$ and in a positive reflector mode. Solution containing saturated sinapinic acid in $50 \%$ acetonitrile with $0.1 \%$ TFA was used as matrix for sample preparation. Briefly, $0.5 \mu \mathrm{L}$ of sinapinic acid solution was coated on the plate followed by 1) depositing $0.5 \mu \mathrm{L}$ solution of salt free leptin-pluronic conjugates in water $\left(10^{-4} \mathrm{M}\right)$, and, 2) coating with $0.5 \mu \mathrm{L}$ sinapinic acid solution. The mass spectrometer was calibrated against insulin $(5729.61 \mathrm{Da})$ and albumin (66429.09 Da) (Sigma-Aldrich Co. St-Louis, MO).

\subsubsection{Sodium dodecyl sulfate polyacrylamide gel electrophoresis (SDS-PAGE)}

-Leptin and leptin-P85 conjugates were prepared in $5 \mu \mathrm{L}$ deionized water at a protein concentration of $2 \mu \mathrm{g} / \mu \mathrm{L}$ (as determined by MicroBCA) and diluted (1:1) with non-reducing denaturing loading buffer ( $3.8 \mathrm{~mL}$ of $\mathrm{H}_{2} \mathrm{O}, 5 \mathrm{~mL}$ of $0.5 \mathrm{M}$ Tris- $\mathrm{HCl}(\mathrm{pH} 6.8), 8 \mathrm{~mL} 15 \%$ $\mathrm{wt} / \mathrm{vol} \mathrm{SDS}, 4 \mathrm{~mL}$ of glycerol, $0.4 \mathrm{~mL}$ of bromophenol blue $1 \% \mathrm{wt} / \mathrm{vol})$. The samples were heated for $5 \mathrm{~min}$ at $100{ }^{\circ} \mathrm{C}$ and then loaded to $15 \%$ precast polyacrylamide Tris- $\mathrm{HCl}$ gel (Bio-Rad Life Science Research, Hercules, CA). After running for $3 \mathrm{hr}$ at $120 \mathrm{~V}$, the gel was fixed in 50\% methanol/10\% acetic acid, stained in SYPRO® Ruby solution and scanned on a Typhoon gel scanner.

2.2.5. Size measurements-Particle size and size distribution were measured by dynamic light-scattering (DLS) using Zetasizer Nano-ZS instrument (Malvern, UK). Leptin samples were prepared at $100 \mu \mathrm{g} / \mathrm{mL}$ concentration in deionized water, sterilized by $0.22 \mu \mathrm{m}$ of sterile Ultrafree-MC centrifugal filter units and kept at equilibrium at $20^{\circ} \mathrm{C}$ for $5 \mathrm{~min}$ prior to measurement. The particle parameters were measured for $15 \mathrm{~min}$ at $25^{\circ} \mathrm{C}$ with a $90^{\circ}$ scattering angle. Mean effective hydrodynamic diameter $\left(D_{\text {eff }}\right)$ and volume-average size distribution were obtained by automatically repeating (six times) the measurement based on the Zetasizer internal setting.

2.2.6. Circular dichroism (CD) spectra-Secondary structure of leptin samples was determined by CD spectra in Chirascan ${ }^{\mathrm{TM}}$-Plus automated CD (ACD) spectrometer (Applied Photophyscs Ltd, UK) using a $10 \mathrm{~mm}$ QS Hellma cuvette. Leptin samples were dissolved in sodium phosphate buffer $(10 \mathrm{mM}, \mathrm{pH} 7.5)$ at a concentration of $0.1 \mathrm{mg} / \mathrm{mL}$. The far UV spectra $(190-260 \mathrm{~nm})$ were recorded at $25^{\circ} \mathrm{C}$ with bandwidth of $1.0 \mathrm{~nm}$, step of $0.5 \mathrm{~nm}$ and time-per-point of $1.25 \mathrm{sec}(50,000$ repeats per point). The results were reported as mean residual molar ellipticity $\left([\theta]\right.$ in degree $\left.\cdot \mathrm{cm}^{2} \cdot \mathrm{dmol}^{-1}\right)$ and calculated using Eq. (1)

$$
[\theta]=(\theta \times 100 \times M) /(C \times l \times n), \quad(1)
$$

where $\theta$ (degree) is the observed ellipticity, $M(\mathrm{~g} / \mathrm{mol})$ is the molecular weight of leptin of $16.14 \mathrm{kDa}, C(\mathrm{mg} / \mathrm{mL})$ is the sample concentration at $0.1 \mathrm{mg} / \mathrm{mL}, l(\mathrm{~cm})$ is the optical path of $0.1 \mathrm{~cm}$ and $n$ is the number of leptin residues of 147 . The secondary structure of leptin samples, in particular the percentage of $\alpha$-helix, $\beta$-strands, $\beta$-turns and remaining structures were determined by computer program CONTIN based on a set of standard CD spectra from 37 proteins reported in literature [31,32]. 
2.2.7. LC/MSMS Orbitrap mass spectrometry-The Lep(ss)-P85 or Lep(ss)-P85(L) was mixed with DTT (10 $\mathrm{mM}$ in phosphate buffer saline (PBS)) at $65^{\circ} \mathrm{C}$ for $5 \mathrm{~min}$ followed by IAA $(10 \mathrm{mM})$ treatment at $30^{\circ} \mathrm{C}$ for $30 \mathrm{~min}$ to block free thiol groups. This removed the bulk of the $\mathrm{P} 85$ molecule but left a remnant $\left(-\mathrm{C}(\mathrm{O}) \mathrm{CH}_{2}-\mathrm{CH}_{2} \mathrm{SCH}_{2} \mathrm{C}(\mathrm{O}) \mathrm{NH}_{2}\right)$ attached to the Lys residues and/or $\mathrm{N}$-terminus at the site of $\mathrm{P} 85$-modification. Samples were filtered through Amicon Ultra centrifuge membrane to remove low molecular mass agents, and precipitated in cold acetone to remove detached P85. Complete detachment of P85 (except the remnant) was verified by SDS-PAGE. The precipitate was digested with trypsin using Filter Aided Sample Preparation (FASP) protocol [33]. The peptide ( $2 \mu \mathrm{g}$ of protein digest/ analysis) was loaded onto a microcapillary fused silica precolumn $(2 \mathrm{~cm} \times 100 \mu \mathrm{m}$ i.d. $)$ and washed with $95 \%$ solvent A ( $0.1 \%$ formic acid in water $) / 5 \%$ solvent B $(0.1 \%$ formic acid in acetonitrile) for $20 \mathrm{~min}$ at a flow rate of $2 \mu \mathrm{L} / \mathrm{min}$, using a Nano-Acquity HPLC system (Milford, MA Waters Corp.). The pre-column was connected to a C18 analytical column (14 $\mathrm{cm} \times 75 \mu \mathrm{m}$ i.d., $5 \mu \mathrm{m}$ particle size) and the flow rate was reduced to $250 \mathrm{~nL} / \mathrm{min}$. Peptides were eluted by increasing solvent B to $40 \%$ over a $2 \mathrm{hr}$ gradient. The effluent from the LC system was electrosprayed directly into an LTQ Orbitrap Velos ion trap mass spectrometer (Thermo Electron Corp.). Data were collected in a data-dependent manner with each cycle consisting of one high-resolution mass spectrum (over a 400-2000 mass to charge $(\mathrm{m} / \mathrm{z}$ ) ratio) taken from initial scan in Orbitrap and ten MSMS fragmentation spectra in LTQ ion trap that were automatically selected from the most abundant ions in subsequent collisionactivated dissociation. The Spectra were searched by MASCOT (V 2.3 from Matrix Science) using Proteome Discoverer program (v 1.3 from Thermo Scientific). The searching parameters included a mass tolerance of $10 \mathrm{ppm}$, fragment ion tolerance of $0.8 \mathrm{Da}$, variable modifications for methionine oxidation, and remnant $\left(-\mathrm{C}(\mathrm{O}) \mathrm{CH}_{2} \mathrm{CH}_{2} \mathrm{SCH}_{2} \mathrm{C}(\mathrm{O}) \mathrm{NH}_{2}\right)$ modification of lysine/ methionine. Peptide assignments were made based on $2 \mathrm{MS} / \mathrm{MS}$ spectra with a Mascot Expectation value of less than 0.01 and at least one was validated manually.

2.2.8. Enzyme-linked immunosorbent assay (ELISA)—The ELISA protocol was kindly provided by Academia Sinica (Taipei, Taiwan). Briefly, 96-well microplates (eBioscience, Inc. San Diego, CA) were coated first for $4 \mathrm{hr}$ at $37^{\circ} \mathrm{C}$ and then overnight at 4 ${ }^{\circ} \mathrm{C}$ with $50 \mu \mathrm{L} /$ well of $5 \mu \mathrm{g} / \mathrm{mL}$ of anti-PEG antibody (AGP4, mouse IgM anti-PEG, Academia Sinica, Taipei, Taiwan) in $35 \mathrm{mM} \mathrm{NaHCO}_{3} / 15 \mathrm{mM} \mathrm{Na}_{2} \mathrm{CO}_{3}$ (pH 9.3), then blocked with 5\% skim milk in PBS for $2 \mathrm{hr}$, and washed thrice with PBS. The analyzed samples in $50 \mu \mathrm{L}$ dilution buffer (2\% skim milk in PBS) were added to each well and incubated for $2 \mathrm{hr}$ at $25{ }^{\circ} \mathrm{C}$. Plates were washed (thrice with $0.05 \%$ Tween 20 in PBS (PBST) and twice with PBS) and supplemented with $50 \mu \mathrm{L} /$ well biotinylated anti-PEG antibody (3.3-biotin, $5 \mu \mathrm{g} / \mathrm{mL}$ in dilution buffer, Academia Sinica, Taipei, Taiwan). After $1 \mathrm{hr}$ at 25 ${ }^{\circ} \mathrm{C}$ the plates were washed and stained for $1 \mathrm{hr}$ with $50 \mu \mathrm{L} /$ well of streptavidin-HRP (1 $\mu \mathrm{g} / \mathrm{mL}$, Jackson ImmunoResearch Lab., West Grove, PA). Finally, the plates were washed again and peroxidase activity was measured by adding $100 \mu \mathrm{L} /$ well tetramethylbenzidine (Thermo Fisher Scientific., Rockford, IL) for 5-30 min followed by $100 \mu \mathrm{L} /$ well of stopping reagent (Thermo Fisher Scientific, Rockford, IL). Absorbance (450 nm) was measured in microplate reader SpectraMax M5 (Molecular devices, Sunnyvale, CA). 
2.2.9. Stability of disulfide bond in leptin-P85 conjugates-The disulfide bond stability was investigated in the presence of human serum, mimicking extracellular conditions, or cytosolic concentration of L-glutathione (reduced), a main contributor of intracellular reductive environment as described in the literature [34-36]. Briefly, leptin or Lep(ss)-P85 (100 $\mu \mathrm{g})$ was mixed with $200 \mu \mathrm{L}$ of sterile-filtered human male AB serum at 37 ${ }^{\circ} \mathrm{C}$. Two microliters of aliquot was sampled from the mixture at desired time point, stored at $-80{ }^{\circ} \mathrm{C}$ and analyzed by standard Western blot using antibody against mouse leptin. The aliquot samples were prepared and electrophoresed as described previously using nonreducing denaturing loading buffer. Western blot was conducted by transferring the nonstained gels to PVDF membrane in Tris/glycine transfer buffer (Bio-Rad) containing 20\% methanol at $60 \mathrm{~V}$ for $2 \mathrm{hr}$, washing thrice in Tris buffered saline (TBS) containing $0.05 \%$ Tween 20 (TBST) and subsequent $1 \mathrm{hr}$ of blocking in 5\% skim milk in TBST at room temperature (RT). To detect the blot, the membrane was probed with anti-leptin polyclonal antibody (AF498, goat IgG anti-mouse leptin, R\&D Systems, Minneapolis, MN) in TBST containing $1 \%$ BSA overnight at $4{ }^{\circ} \mathrm{C}$. After washing in TBST 3 times, the membrane was incubated with donkey anti-goat IgG-HRP (1:10,000, Santa Cruz biotechnology, Inc. Dallas, TX) at RT for $1 \mathrm{hr}$, washed thrice in TBST and twice in TBS, and then visualized using ECL detection kit (Thermo Fisher Scientific, Rockford, IL). Densitometry analysis was conducted using Image J (v1.47, NIH, USA) and data were presented from three independent Western blot experiments.

To study the stability of disulfide linker upon L-glutathione (reduced) treatment, Lep(ss)-P85 or Lep(cc)-P85 (a control sample prepared using a non-degradable linker DSS, $50 \mu \mathrm{g}$ in 500 $\mu \mathrm{L}$ PBS, $\mathrm{pH}$ 7.4) were dialyzed in FLOAT-A-LYZER (8-10 kDa) against PBS containing

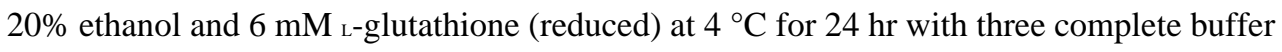
changes. Samples were then purified using Amicon Ultra $0.5 \mathrm{~mL}$ centrifugal filters to remove excess of reducing re-agent. Protein content was measured using reducing agent compatible BCA Protein Assay (Thermo Fisher Scientific, Rockford, IL). Samples were also analyzed by mass spectra and SDS-PAGE to confirm the disul-fide bond reduction and stored at $-20{ }^{\circ} \mathrm{C}$ for further measurement of $\mathrm{CD}$ spectra and binding affinity.

2.2.10. Surface plasmon resonance (SPR)—The binding affinity of leptin-P85 conjugates was measured by SPR in Biacore3000 instrument (GE Healthcare, Piscataway, $\mathrm{NJ}$ ), using a method reported previously for leptin [37]. To prepare the sensor chip, protein G was immobilized on CM5 (Channel A and B) by consequent injection of 1) $115 \mu \mathrm{L}$ NHS/EDC (1:1, vol/vol) (to activate dextran surface); 2) $60 \mu \mathrm{L}$ protein $\mathrm{G}(200 \mu \mathrm{g} / \mathrm{mL}, 10$ $\mathrm{mM}$ sodium acetate buffer, $\mathrm{pH}$ 4.0) (to bind the surface at 2000-3000 resonance units (RU)), and 3) $75 \mu \mathrm{L}$ of $1 \mathrm{M}$ ethanolamine hydrochloride, $\mathrm{pH} 8.5$ (to deactivate NHS-ester and remove electrostatically bound protein). The $\mathrm{Fc}$ fragment of $\mathrm{ObR}-\mathrm{Fc}$ was used to reversibly bind to protein $\mathrm{G}$ that was pre-immobilized onto the sensor chip. The ObR-Fc N-terminus represented the extracellular domain of the putative leptin transporter at the BBB (ObRa) that interacts with circulating leptin; it also shared the sequence of leptin receptor (ObRb) expressed in the brain for leptin binding and signal activation. Therefore, the ObR-Fc Nterminus was adsorbed onto the sensor chip to detect leptin sample for binding affinity measurement which could reflect leptin activity at both of the BBB level and its central 
receptor site. CM5 surface response was recorded by first, immobilization of ObR-Fc ( 0.5 $\mu \mathrm{g} / \mathrm{mL}, 15 \mu \mathrm{L}$ in HBS-EP, $5 \mu \mathrm{L} / \mathrm{min}$ flow rate) in channel A following $1800 \mathrm{~s}$ washing (to capture 100-300 RU of ObR-Fc); second, capture of leptin or leptin-P85 conjugates (0-300 $\mathrm{nM}, 100 \mu \mathrm{L}$ in HBS-EP, flow rate $20 \mu \mathrm{L} / \mathrm{min}$ ) and dissociation (900 s) in channel A (ObRFc surface) and B (protein G surface); third, regeneration of a fully active protein $\mathrm{G}$ surface by $5 \mu \mathrm{L}$ glycine ( $10 \mathrm{mM}, \mathrm{pH} 2.0$ ). The data (sensorgrams in channel $\mathrm{A}$ ) were corrected by non-specific protein $\mathrm{G}$ surface binding (sensorgrams in channel $\mathrm{B}$ ) and baseline drift (sensorgrams of HBS-EP injection in channel A) which can occur due to a slow dissociation of $\mathrm{ObR}-\mathrm{Fc}$ and protein $\mathrm{G}$ and then fitted to a 1:1 binding model using BIA evaluation software 3 . The rate constants $k_{\mathrm{a}}$ and $k_{\mathrm{d}}$ were derived from these association and dissociation data using nonlinear least square $\left(\chi^{2}\right)$ analysis model and further used to calculate the equilibrium dissociation constants $\left(K_{\mathrm{D}}\right)$. The values shown represent average of three separate measurements.

2.2.11. Cell proliferation assay-The proliferation assay was conducted in $\mathrm{BaF} / 3$ cells transfected with the long form of human leptin receptor (hObR). Cells were cultured in RPMI-1640 medium containing 10\% fetal bovine serum, $50 \mu \mathrm{M}$ 2-mercaptoethanol, 20 $\mathrm{ng} / \mathrm{mL}$ rhleptin and $0.5 \mathrm{mg} / \mathrm{mL}$ of geneticin. To conduct proliferation assay, the cells were harvested, washed and re-suspend at $2 \times 10^{5}$ cells $/ \mathrm{mL}$ in $50 \mu \mathrm{L} /$ well of RPMI-1640 medium in a 96-well plate. Leptin or leptin-P85 conjugates were diluted in the same medium at various concentrations from 0 to $50 \mu \mathrm{g} / \mathrm{mL}$ and added to the plate in duplicate at $50 \mu \mathrm{L} /$ well. The plate was incubated at $37^{\circ} \mathrm{C}$ for 3 days and during the final $16-20 \mathrm{hr}$ of incubation period, $10 \mu \mathrm{L} /$ well of a $0.1 \mathrm{mg} / \mathrm{mL}$ resazurin was added. Cell proliferation was assessed by measuring the fluorescent intensity at the excitation wavelength of $544 \mathrm{~nm}$ and at emission wavelength of $590 \mathrm{~nm}$. The data were analyzed using a 4-parameter fit and the activity was interpreted as $\mathrm{IC}_{50}$.

\subsection{Feeding study}

The feeding study was conducted in St. Louis University School of Medicine using procedures that are approved by the National Institutes of Health Guide for Care and Use of Laboratory Animals. Male ob/ob mice, 8 weeks of age, were purchased from Jackson laboratories (Bar Harbor, MA). Male CD-1 from in house colony was placed into two groups at 3 weeks of age. This mouse has been used by us and others in DIO models [38]. To produce DIO mice, one group was placed on regular chow (5001 rodent diet, PMI Nutritional International, Brentwood, $\mathrm{MO} ; 4.5 \%$ fat) and one group was placed on breeder chow (Teklad mouse breeder diet, Harlan-Teklad, Madison, WI; 10\% fat) for 4 months. At the end of this time, total body weights were $40.4 \pm 2.81$ (mean \pm SD) in regular chow mice (estimated $10 \mathrm{~g}$ of body fat 30) and $58.1 \pm 6.3 \mathrm{~g}$ (estimated $30 \mathrm{~g}$ of body fat) in breeder chow mice. Mice were individually housed prior to the start of the food intake studies. $\mathrm{Ob} / \mathrm{ob}$ mice were weighted. Mice were then given a subcutaneous (s.c.) injection of either Lep(ss)-P85 (40 $\mu \mathrm{g} / \mathrm{day}$ ) or vehicle. On days 2 and 3 mice food and body weights were taken and mice were given s.c. injection of the same dose of Lep(ss)-P85 or vehicle. On day 4 food and body weights were taken. This design is similar to our previous study in ob/ob mice [38]. In the study using DIO mice, mice were food deprived overnight. In one group of mice intracerebroventricular (i.c.v.) surgery was applied using the procedure described 
previously [29]. Prior to drug treatment, mice were lightly anesthetized with isoflurane, and an injection of Lept(ss)-P85 (25 $\mu \mathrm{g})$ or vehicle was given i.c.v. In another group, mice received an i.v. injection of Lep(ss)-P85 (3 mg) or vehicle via tail vein. For both groups 15 min. post injection a known amount of food was placed in the cage. Two and $24 \mathrm{hr}$ later the food was weighted to determine $2 \mathrm{hr}$ and $24 \mathrm{hr}$ intake.

\subsection{PK studies}

2.4.1. Radioactive labeling -Leptin or leptin-P85 conjugates were radioactively labeled by chloramine-T method as previously described for Lep(ss)-P85 [29]. Briefly, $5 \mu \mathrm{g}$ of leptin or $10 \mu \mathrm{g}$ of leptin analogs was mixed with $1 \mathrm{mCi} \mathrm{Na}{ }^{131}$ I or $0.5 \mathrm{mCi} \mathrm{Na}^{125} \mathrm{I}$ (PerkinElmer Life Sciences, Boston, MA), respectively, in a final volume of $45 \mu \mathrm{L}$ sodium phosphate buffer $(0.25 \mathrm{M}, \mathrm{pH} 7.5)$. A freshly made $10 \mu \mathrm{g}$ of chloramine-T solution ( $2 \mu \mathrm{g} / \mu \mathrm{L}$, in $5 \mu \mathrm{L}$ sodium phosphate buffer) was added to the mixture; after $60 \mathrm{~s}$ incubation with mixing, the radioactively labeled substance was purified with Illustra NAP-5 columns (GE Healthcare, Piscataway, NJ). Fractions were collected in Eppendorf tubes pretreated with $1 \%$ BSA in lactated Ringer's solution (1\% BSA-LR) to prevent non-specific absorbance and counted in a PerkinElmer $\gamma$-counter. Similarly, albumin was labeled by $\mathrm{Na}^{131} \mathrm{I}$ using chloramine-T method and purified with Illustra NAP-5 columns. TCA precipitation was conducted to determine the iodine association of labeled samples. Briefly, $1 \mu \mathrm{L}$ of collected fractions was added to $0.5 \mathrm{~mL}$ of $1 \%$ BSA-LR and then precipitated in $0.5 \mathrm{~mL}$ of $30 \%$ TCA followed by centrifuging at $5400 \mathrm{~g}$ for $10 \mathrm{~min}$ at $4{ }^{\circ} \mathrm{C}$. The resulting supernatant and pellet were counted in a $\gamma$-counter and the values used to calculate the percent of radioactivity that was precipitated with acid. Samples containing N100,000 cpm/ $\mu \mathrm{L}$ of radioactivity and N90\% precipitation from TCA were used for the animal studies.

2.4.2. Animal procedures-The $\mathrm{PK}$ experiments were conducted in CD-1 male mice (8 to 10 weeks of age) (Charles River Laboratories, Wilmington, Mass) in the Department of Medicine, University of Washington under an approved IACUC protocol. The mice had free access to food and water and were maintained on a 12-hr dark/light cycle in a room with controlled temperature $\left(24 \pm 1{ }^{\circ} \mathrm{C}\right)$ and humidity $(55 \% \pm 5 \%)$. Mice were anesthetized with an i.p. injection of $0.2 \mathrm{~mL}$ of urethane $(4.0 \mathrm{~g} / \mathrm{kg}$ ). Radioactively labeled substances were i.v. injected into the jugular vein in a volume of $0.2 \mathrm{~mL}$ of $1 \%$ BSA-LR. Blood from the preexposed right carotid artery was collected at various time points after injection; mice were immediately decapitated and then the whole brain was removed and weighed. In some cases, a procedure that washed out the vascular contents of the brain was performed before decapitation. In these animals, the arterial blood was collected from the abdominal aorta in an open abdomen prior to wash out. After the collection of the arterial blood, the thorax was opened, the descending thoracic was clamped, both jugular veins were severed, the heart was exposed, and 1\% BSALR was perfused into the left ventricle of the heart over $1 \mathrm{~min}$. Finally, the mouse was decapitated and the whole brain removed and weighed.

2.4.3. Serum clearance, influx rate and brain vascular volume-Mice were given an i.v. injection of $300,000 \mathrm{cpm}$ of ${ }^{125} \mathrm{I}-\mathrm{Lep}(\mathrm{ss})-\mathrm{P} 85(\mathrm{~L})$ or ${ }^{125} \mathrm{I}$-Lep(ss)-P85(H) co-injected with 300,000 cpm of ${ }^{131}$ ILep. Blood and brain samples were collected between 2 and 90 min after i.v. injection. In a separate study, mice were given an i.v. injection of 300,000 cpm 
of an ${ }^{125}$ I-leptin analogs with $300,000 \mathrm{cpm}$ of ${ }^{131} \mathrm{I}$-albumin ( ${ }^{131} \mathrm{I}$-Alb); brain and serum were collected between 2 and $180 \mathrm{~min}$ after injection. The arterial blood was centrifuged at $5400 \mathrm{~g}$ for $10 \mathrm{~min}$ at $4{ }^{\circ} \mathrm{C}$, and the serum was collected. The levels of radioactivity in serum $(50 \mu \mathrm{L})$ and brain samples were counted in the dual channel $\gamma$-counter. At the end of the experiment, the radioactivity of the material from the injection vial was counted and used to determine the amount of material administered. For samples containing both of ${ }^{125} \mathrm{I}$ and ${ }^{131} \mathrm{I}$ radioactivity, radioactivity levels were measured in the dual channel $\gamma$-counter capable of distinguishing between the two isotopes. To calculate the clearance from serum, the level of radioactivity was expressed relative to the amount injected $(\% \mathrm{Inj} / \mathrm{mL})$ and these values were plotted against time (min) to obtain the serum concentration vs time curve. The brain/serum ratios for ${ }^{131} \mathrm{I}$-leptin or for ${ }^{125} \mathrm{I}$-leptin analogs were expressed in units of $\mu \mathrm{L} / \mathrm{g}$ of brain. In some cases, the brain/ serum ratio for ${ }^{125}$ I-leptin analogs was corrected for the vascular space by subtracting the brain/serum ratio of the co-injected ${ }^{131} \mathrm{I}$-Alb in each individual mouse. These brain/serum ratios were then plotted against exposure time and multiple-time regression analysis used to calculate the blood-to-brain unidirectional influx rate (Ki) and volume of distribution for brain (Vi), using Eq. (2) $[39,40]$.

$$
A m / C p t=K i\left[\int_{0}^{t} C p(t) \mathrm{d} t / C p(t)\right]+V i
$$

where the brain/serum ratio $(\mathrm{Am} / \mathrm{Cpt})$ is calculated by $\mathrm{cpm} / \mathrm{g}$ of brain $(\mathrm{Am})$ normalized by cpm per microliter of arterial serum at time $t(\mathrm{Cpt})$; the exposure time $\left(0^{t} \mathrm{Cp}(t) \mathrm{dt} / \mathrm{Cp}(t)\right)$ was calculated as the area under the serum concentration time curve divided by the serum concentration at time $t$.

The slope for the linear portion of the relation between the brain/ serum ratios and respective exposure times is $\mathrm{Ki}$, measured in units of $\mu \mathrm{L} / \mathrm{g} \cdot \min$ and representing the rate at which compounds are moving across the BBB from the circulation into the brain parenchyma; The $y$-intercept of the line represents $\mathrm{Vi}$, the apparent volume of material that is distributed to the brain parenchyma at time 0 , measured in $\mu \mathrm{L} / \mathrm{g}$ of tissue weight.

2.4.4. Stability of serum and brain samples-Mice were given i.v. injection of $300,000 \mathrm{cpm}$ of an ${ }^{125} \mathrm{I}$-leptin analog that also contained $300,000 \mathrm{cpm}$ of ${ }^{131} \mathrm{I}$-leptin. Arterial blood and brain were collected at 15, 60 and $240 \mathrm{~min}$ after injection and the stability was determined by TCA precipitation. In a separate group, mice were given an i.v. injection containing $1,000,000 \mathrm{cpm}$ of an ${ }^{125} \mathrm{I}$-leptin analog and 1,000,000 cpm of ${ }^{131} \mathrm{I}$-leptin. Prior to brain and serum collection, a brain washout was performed as described previously at 240 min following administration. The blood sample was processed as described previously and the resulting serum $(50 \mu \mathrm{L})$ was precipitated in $0.5 \mathrm{~mL}$ of $1 \%$ BSA-LR with $0.5 \mathrm{~mL}$ of $30 \%$ TCA followed by centrifugation. The brain sample was homogenized in $3 \mathrm{~mL}$ of sodium phosphate buffer $(0.25 \mathrm{M}, \mathrm{pH} 7.5)$ for 10 strokes, and then centrifuged at $5400 \mathrm{~g}$ for $10 \mathrm{~min}$ at $4{ }^{\circ} \mathrm{C}$. The obtained brain supernatant was then precipitated in an equal volume of $30 \%$ TCA followed by centrifugation. To correct for the degradation of radioactivity during the ex-vivo processing, serum or brain from untreated animals was directly exposed to radioactively labeled samples and then processed identically as above. The radioactivity in acidified serum and brain supernatants and pellets as well as the processing controls were 
counted in a $\gamma$-counter. The stability of serum and brain samples was accessed by the percent of radioactivity precipitated in the pellet and normalized by the values for processing controls.

2.4.5. Brain uptake-Mice received an i.v. injection of ${ }^{125} \mathrm{I}$-Lep(ss)-P85(L) or ${ }^{125} \mathrm{I}$ Lep(ss)-P85(H) with a co-injection of ${ }^{131}$ I-leptin as described in Section 2.4.3. Brain samples were collected $240 \mathrm{~min}$ after injection from animals without brain washout. Brain uptake was calculated using Eq. (3) to obtain the percent of the injected dose entering each gram of brain tissue (\% Inj/g). These values were further corrected for the sample stability assessed based on acid precipitation.

$$
\% \operatorname{Inj} / \mathrm{g}=100(A m / C p t-V i) C p t / \operatorname{Inj}
$$

2.4.6. Inhibition study - To determine the role of the BBB transporter in the BBB penetration of the leptin analogs, $10 \mu \mathrm{g} /$ mouse of nonradioactive recombinant leptin was coinjected with ${ }^{125} \mathrm{I}$-Lep(ss)-P85(L) and ${ }^{131} \mathrm{I}$-leptin or ${ }^{125} \mathrm{ILep}(\mathrm{ss})-\mathrm{P} 85(\mathrm{H})$ and ${ }^{131} \mathrm{I}$-leptin in the $0.2 \mathrm{~mL}$ of $1 \%$ BSA-LR into the jugular vein of CD-1 mice. Blood and brain samples were collected $30 \mathrm{~min}$ after i.v. injection and processed as described previously. Samples were counted in a dual channel $\gamma$-counter. Brain to serum ratio was calculated for each isotope in each group ( $n=10$ /group).

2.4.7. Statistical analysis-Statistical analysis was done using Student's $t$-test for two groups and one-way ANOVA followed by Newman-Keuls multiple comparison test. A minimum $p$ value of 0.05 was estimated as the significance level. Statistic analysis was done with the Prism 5.0 software (GraphPad, San Diego, CA, USA).

\section{Results}

\subsection{Effect of leptin-P85 conjugates on feeding in obese mice}

Leptin-P85 conjugates in this work were produced by modifying leptin primary amino groups (Lys residues and N-terminal) with NHS-activated mono-amine P85 using disulfidecontaining linker (Scheme 1). The conjugate obtained using this chemistry, Lep(ss)-P85 was reported previously [29]. This conjugate as discussed below contains several modified forms of leptin along with unmodified leptin. It was shown to maintain biological activity in reducing food intake of normal CD1 mice at a dose of $4 \mu \mathrm{g}$ per mouse following i.c.v. injection or at a dose of $3 \mathrm{mg}$ per mouse following tail vein injection. To further confirm the biological effect of this conjugate in obese mice, here we reported the acute food intake response of Lep(ss)-P85 in ob/ob mice and DIO mice. After 3 days of treatment, s.c. injection of Lep(ss)-P85 at dose of $40 \mu \mathrm{g}$ per mouse induced significant weight loss $(p<$ $0.006)$ and a decrease of food intake $(p<0.02)$ in ob/ob mice ( $n=6 \sim 7$ /group) (Fig. 1). Direct administration of Lep(ss)-P85 at $25 \mu \mathrm{g}$ per mouse into the lateral ventricle of the brain in DIO mice drastically reduced food intake, a 18\% decrease over the next $24 \mathrm{hr}(n=$ 5/group, $p<0.03$ ), comparing to that in the control group that received the vehicle injection (Fig. 2A). The reduced food intake was also observed in DIO mice $2 \mathrm{hr}(p<0.001)$ and 24 
$\mathrm{hr}(p<0.0001)$ after tail vein injection of Lep(ss)-P85 at a dose of $3 \mathrm{mg}$ per mouse $(n=10 /$ group) (Fig. 2B and C).

\subsection{Purification and characterization of leptin-pluronic conjugates}

\subsubsection{Fractionation and analysis of conjugates by HPLC-In spite of}

demonstrated biological activity and previously reported improvements in brain PK profile, the initial Lep(ss)-P85 conjugate was a fairly heterogeneous product that contained unmodified leptin and leptin modified with 1 or more P85 chains. To improve its purity and homogeneity, a fractionation method by SEC was established to remove the majority of unmodified leptin and isolate leptin modified with 1 P85 chain and multiple P85 chains (Fig. 3A). In SDS-PAGE (Fig. 3B) the fraction eluted at $8.8 \mathrm{~min}$ (Lep(ss)-P858.8 min) displayed a major MW band (indicated by arrow in Lane C), corresponding to leptin modified with 2 P85 chains and a smear above the band, representing leptin modified with 3 or more P85 chains. The major band corresponding to fraction eluted at $9.5 \mathrm{~min}$ (Lep(ss)-P85 $9.5 \mathrm{~min}$ ) was leptin modified with 1 P85 chain (indicated by arrow in Lane D). Characterization of these fractions by mass spectra further confirmed that HPLC SEC was able to reduce the heterogeneity, resulting in Lep(ss)-P85 9.5 min containing mainly 1 P85 chain (mass peak detected at $21 \mathrm{kDa}$ ) and Lep(ss)- P85 8.8 min containing mainly 2 and 3 P85 chains (mass peak detected at 26 and $31 \mathrm{kDa}$ ) (Fig. 3C). Therefore, Lep(ss)-P859.5 min and Lep(ss)P85 8.8 min were further designated as Lep(ss)-P85(L) and Lep(ss)-P85(H), respectively.

The elution profile (Fig. 3A) was generally similar to that previously observed during fractionation of pluronic-modified superoxide dismutase (SOD1) using the TSKgel G3000SW SEC column [41]. While both methods were adopted from purification of SOD1PEG (PEG at $5 \mathrm{kDa}$ ) [42], the elution resolution for these P85 modified proteins was notably lower than that for SOD1-PEG, most likely due to the effect of the hydro-phobic PPO block of pluronic. To tackle the problem, we attempted to purify Lep(ss)-P85 using hydrophobic interaction chromatography (HIC). After optimization of elution conditions, we were able to isolate leptin attached with 1 P85 chain (Lep(ss)-P85(L)) from unmodified leptin but the elution of the more hydrophobic species, Lep(ss)- P85(H), did not succeed (Supplementary data Fig. S1).

3.2.2. Particle size and protein secondary structure-The DLS measurements of the particle size for the $100 \mu \mathrm{g} / \mathrm{mL}$ of native leptin, Lep(ss)-P85, Lep(ss)-P85(L) and Lep(ss)-P85(H) in distilled water resulted in the $D_{\text {eff }}$ values of $3.8 \pm 0.2 \mathrm{~nm}$ (PDI 0.27), 15 $\pm 1 \mathrm{~nm}$ (PDI 0.43), $10.4 \pm 3.5 \mathrm{~nm}$ (PDI 0.60) and $\underline{8.4} \pm 0.4 \mathrm{~nm}$ (PDI 0.68) respectively. The increased size and PDI indices observed for the conjugate samples, were probably, due to self-assembly of Pluronic-modified protein in an aqueous solution.

The secondary structures of leptin and Lep(ss)-P85 conjugates were analyzed using CD spectra (Fig. 4A). Consistent with the literature, recombinant mouse leptin exhibited high content of a-helix (67\%) featured by negative bands at 208 and $222 \mathrm{~nm}$, no $\beta$-sheet and $8 \%$ of $\beta$-turn [43]. The CD spectrum of Lep(ss)-P85 (un-fractionated mixture) was generally similar to that of leptin suggesting presence of $49 \%$ a-helix, $20 \% \beta$-turn and absence of $\beta$ sheet. Overall the $\mathrm{CD}$ data indicated the proper protein folding. However, changes in signal 
intensity, a decrease in $\alpha$-helix and an increase in $\beta$-sheet content in Lep(ss)-P85 suggest that leptin has undergone some conformation changes in the course of the modification.

3.2.3. Identification of modification sites in leptin-P85 conjugates-Mouse recombinant leptin contains eight primary amino groups (seven Lys residues and the $\mathrm{N}$ terminus), which all could be modified (Supplementary data Fig. S2). The site(s) of modification was determined by LC/MSMS Orbitrap mass spectrometry. Of the eight primary amino groups, five modification sites (Lys 6, 12, 16, 34 and 107) were identified in both of Lep(ss)-P85 and Lep(ss)-P85(L) conjugates (Fig. S2).

\subsubsection{Immunoassays of leptin-P85 conjugates using Anti-PEG antibody-To}

confirm the presence of P85 in leptin conjugates, a double sand wich ELISA was performed using the monoclonal anti-PEG backbone antibody AGP4 and 3.3-biotin. Previously these antibodies were successfully used to assay PEGylated proteins and nanoparticles [44-49]. In this work using ELISA we were able to quantitatively measure PEGSOD1 (5 kDa PEG, multiple PEG chains) and Lep(ss)-P85 at concentrations as low as ca. $0.001 \mu \mathrm{g} / \mathrm{mL}$ and 0.1 $\mu \mathrm{g} / \mathrm{mL}$ respectively (Fig. 4B). In contrast, no signal was observed for free P85 and native leptin. Moreover, this ELISA did not recognize Lep(ss)-P85(L) that contained a single P85 chain; this finding was consistent with the prior report, in which a similar ELISA assay failed to recognize lysozyme modified with a single PEG chain of $2 \mathrm{kDa}$ or $5 \mathrm{kDa}$ [49]. Finally, no ELISA signal was observed for SOD1 modified with multiple pluronic L81, a copolymer with nearly the same length of PPG but much shorter PEG block compared to P85 (Supplementary data Fig. S3), indirectly suggesting that AGP4 antibody is selective to PEG rather than PPG. Altogether, these results suggest that the anti-PEG antibody recognizes P85 chains linked to leptin. However, quantitative measurement using this antibody was only possible for leptin-P85 conjugates containing multiple P85 chains. Moreover, in addition to the number of polymer chains linked to the polymer this assay is dependent on the length of PEG block. The used ELISA assay relies on the ability of both the capture and detection antibodies (AGP3 and biotin3.3) to bind with the PEG chain to detect the PEGylated protein. Lep(ss)-P85(L) contains leptin modified with a single P85 chain, carrying approximately $2.3 \mathrm{kDa}$ PEG molecule. To produce positive ELISA signal both AGP3 and biotin 3.3 would need to bind with the same fairly short PEG chain, which most likely is sterically hindered. Similarly, the free P85, once it is captured by AGP3, possibly cannot be detected by biotin 3.3 because of the steric hindrance.

3.2.5. Disulfide bond stability in serum-To examine stability of the disulfide bond in the presence of serum, Lep(ss)-P85 or leptin (control) was incubated with human serum (0.5 $\mu \mathrm{g} / \mu \mathrm{L}$ ) at $37^{\circ} \mathrm{C}$ for up to $24 \mathrm{hr}$ and analyzed by Western blot using anti-leptin antibody. There was no change in the profile of native leptin showing one major band at $16 \mathrm{kDa}$ corresponding to monomeric form at either 0 or $24 \mathrm{hr}$. Lep(ss)-P85 contained multiple species, including a monomeric and a dimer form of leptin (16 and $32 \mathrm{kDa})$, and leptin conjugates modified by one, two and multiple P85 chains (as indicated by arrows) (Fig. 5). Although there were some apparent changes in the density of bands, the differences particularly for the leptin monomer were marginal (Supplementary data Fig. S4). Most importantly, Lep(ss)-P85 conjugate at all time points displayed similar bands. These results 
suggest that Lep(ss)-P85 remains stable in serum for at least $24 \mathrm{hr}$ with little if any disulfide bond reduction and release of $\mathrm{P} 85$.

3.2.6. In Vitro binding of leptin-P85 conjugates to the leptin receptor-The in vitro activity of leptin-P85 conjugates was examined by SPR and cell proliferation assays. The SPR association and dissociation pro-files were recorded for native leptin, Lep(ss)-P85, Lep(ss)-P85(L), and a mixture of native leptin and free P85 copolymer (Fig. 6A). The resulting kinetic constants, $k_{\mathrm{a}}$ ("on rate") and $k_{\mathrm{d}}$ ("off rate") were used to calculate $K_{\mathrm{D}}$ (Table 1). Native leptin displayed extremely fast association and slow dissociation phases, resulting in a $K_{\mathrm{D}}$ of ca. $10^{-10} \mathrm{M}$. This activity was of the same order of magnitude as previously reported value [37]. Interestingly, the binding affinity for the leptin and P85 mixture decreased 3 fold, suggesting that free P85 interferes with interaction of native leptin with its receptor. The Lep(ss)-P85 mixture including modified leptin conjugates with multiple P85 chains displayed a dramatic decrease in the binding affinity as exhibited by 500 fold increase in $K_{\mathrm{D}}$ compared to that of the native leptin. In contrast, a more homogenous sample Lep(ss)-P85(L) with low degree of modification displayed much higher binding affinity, although it was still 12 fold less active than the native leptin. The in vitro activity was further measured by a cell-based proliferation assay using in $\mathrm{BaF} / 3-\mathrm{hObR}$ cells. Here the results were somewhat different. Based on this assay, $\mathrm{IC}_{50}$ of mouse recombinant leptin was $0.08 \mathrm{ng} / \mathrm{mL}$, consistent with the activity reported from its vendor, R\&D System. The $\mathrm{IC}_{50}$ of Lep(ss)-P85(L) and Lep(ss)-P85(H) decreased about 14 and 18 fold respectively compared to that of unmodified leptin (Fig. 6B and Table 1). Surprisingly, Lep(ss)- P85 displayed high activity in the proliferation assay relative to activity shown in the SPR study, with $\mathrm{IC}_{50}$ of Lep(ss)-P85 being only 5 fold less than $\mathrm{IC}_{50}$ of leptin. The presence of unmodified leptin in the Lep(ss)- P85 mixture appears to explain relatively higher activity shown in the proliferation assay by this mixture compared to purified Lep(ss)- P85(L) and Lep(ss)-P85(H) forms.

3.2.7. Disulfide bond cleavage in Lep(ss)-P85 conjugates-We posit that the disulfide bond in the Lep(ss)-P85 conjugate may be cleaved in the biological milieu. Therefore, the disulfide bond stability was studied by exposing Lep(ss)-P85 samples to Lglutathione (reduced), a major chemical that contributes to the reductive intracellular environment. The disulfide bond in the Lep(ss)-P85 conjugate was considerably, albeit not completely reduced after $24 \mathrm{hr}$ incubation with L-glutathione (reduced). This was evident in mass spectra by the disappearance of a signal for leptin modified with two P85 chains and a decrease of a signal for leptin modified with one P85 chain (Supplementary data Fig. S5). In comparison to the non-degradable analog, Lep(cc)-P85 did not display any change in the mass spectra before or after treatment by L-glutathione (reduced) (Supplementary data Fig. S5). Notably, both Lep(ss)-P85 and its reduced form, Lep(s $\neq$ s)-P85 exhibited almost identical CD spectra, showing some decrease in a-helix and increase in $\beta$-sheet content compared to native leptin (Fig. 4A). Thus, removal of the P85 chain from leptin did not result in a recovery of the secondary structure of leptin to its native form. That could be due to the presence residual groups, $-\mathrm{C}(\mathrm{O}) \mathrm{CH}_{2} \mathrm{CH}_{2} \mathrm{SH}$ or $-\mathrm{C}(\mathrm{O}) \mathrm{CH}_{2} \mathrm{CH}_{2} \mathrm{~S}$-glutathione, which may remain attached to the leptin amino groups after cleavage of the $\mathrm{P} 85$ moiety from Lep(ss)-P85 (Fig. S2). However, another possibility is that the leptin secondary structure 
was affected during its exposure to L-glutathione (reduced), for example, as a result of thiol exchange reaction with the unique disulfide bond of leptin (Fig. S2). In favor of this suggestion is that the treatment of native leptin with $\mathrm{L}$-glutathione (reduced) also produced a similar CD spectrum to that of Lep(ss)-P85 (Fig. 4A). In spite of minimal changes in its secondary structure, according to the SPR assay Lep(s $\neq$ s)-P85 did exhibit a higher binding affinity as shown by 3 fold decrease in the dissociation constant $K_{\mathrm{D}}$ compared to that of the non-reduced Lep(ss)-P85 form (Table 1). Therefore after cleavage of P85 in vitro Lep(ss)P85 partially regained the receptor binding affinity although it never reached the level observed for the native leptin.

\subsection{PK of Lep(ss)-P85 conjugates}

The brain PK profile of leptin-pluronic conjugate, Lep(ss)-P85 has been previously reported by us [29]. In brief when compared to native leptin after i.v. injection Lep(ss)-P85 had a longer half-life in blood and similar influx rate across the BBB. Here we determined three major components of this Lep(ss)-P85 mixture: unmodified leptin, Lep(ss)-P85(H) and Lep(ss)-P85(L)). These components would have collectively contributed to the PK profile in our prior study. Thus, we radioactively labeled each component and studied their serum clearances and brain uptakes.

3.3.1. Serum clearance-To compare the PK profiles of leptin and leptin-P85 conjugates, we co-injected ${ }^{131}$ I-leptin with ${ }^{125}$ I-labeled conjugates to each animal, collected the brain and serum samples, and measured ${ }^{125} \mathrm{I}$ and ${ }^{131} \mathrm{I}$ radioactivity for each sample. Statistical comparisons of these results thus minimize the variability originating among individual animals as two compounds are assessed in each animal. The serum clearance curve was obtained by plotting serum radioactivity $(\% \mathrm{In} / \mathrm{mL})$ vs. time (min). A first-order kinetics was observed for the early phase of clearance of all substances, which was demonstrated by the statistically signifi-cant relation between $\log (\% \mathrm{Inj} / \mathrm{mL}$ ) and time $t$ (Fig. 7). Serum half-life $\left(t_{1 / 2}\right)$ of leptin, Lep(ss)-P85(L) and Lep(ss)-P85(H) was $11.98 \mathrm{~min}$, $40.75 \mathrm{~min}$ and $75.8 \mathrm{~min}$ respectively, suggesting that pluronic modification prolonged leptin circulation, with a higher number of P85 chains attached to the protein producing a longer circulation time. The serum half-life for the unpurified conjugates, Lep(ss)-P85, was reported previously at $32.35 \mathrm{~min}$ [29], consistent with that being a mixture of all three forms of leptin. The initial vascular volume distribution for all three substances was not significantly different from each other, indicating that the addition of pluronic moieties did not alter distribution of leptin outside of the vasculature.

3.3.2. Influx rate across the BBB-The brain/serum ratios were plotted vs. exposure times and analyzed by multiple-time regression (Fig. 8). In this analysis the slope of the linear portion of the plot determined the blood-to-brain unidirectional influx rate, $\mathrm{Ki}$ and the Y-intercept determined the distribution volume in brain at $t=0(\mathrm{Vi})$. The previously reported value of Ki of Lep(ss)-P85 mixture at the BBB was $0.272 \pm 0.037 \mu \mathrm{L} / \mathrm{g} \cdot \mathrm{min}$, which is not statistically different from Ki of leptin [29,50]. Here, both Lep(ss)-P85(L) and Lep(ss)-P85(H) crossed the BBB at a slower rate than the co-injected leptin (Fig. 8A and B), as shown by their ca. 6.2 to 6.4-fold lower influx rates $\left(\mathrm{Ki}_{\mathrm{Lep}(\mathrm{ss})-\mathrm{P} 85(\mathrm{~L})}=0.038 \pm 0.008\right.$ $\mu \mathrm{L} / \mathrm{g}$ min vs Ki $i_{\text {Lepti }} n=0.236 \pm 0.017 \mu \mathrm{L} / \mathrm{g} \cdot \min , \mathrm{Ki}_{\mathrm{Lep}(\mathrm{ss})-\mathrm{P} 85(\mathrm{H})}=0.020 \pm 0.007 \mu \mathrm{L} / \mathrm{g} \cdot$ 
min vs $\left.\mathrm{Ki}_{\text {Lepti } \mathrm{n}}=0.129 \pm 0.011 \mu \mathrm{L} / \mathrm{g} \cdot \min \right)$. The initial volume of brain distribution was also reduced for both purified conjugates. Both Lep(ss)-P85(L) and Lep(ss)-P85(H), however, did cross the BBB at a rate faster than albumin. This was evident from positive values of their influx rates corrected for the vascular space using co-injected albumin (Fig. $8 \mathrm{C}$ and $\mathrm{D})$.

3.3.3. Stability of serum and brain samples-The stability of leptin-P85 conjugates in serum and brain was assayed using acid precipitation, a previously established method allowing to estimate the integrity of the iodinated leptin [4]. As shown in Table 2, the percentage of radioactivity recovered from serum and brain, as an indicator of the protein integrity, was highest in the Lep(ss)-P85(H) group, followed by Lep(ss)-P85(L) group and lowest in the leptin group. It is notable that this difference was negligible for samples collected at 15 min following i.v. injection when degradation of the leptin and its analogs was minimal. However, at the later time points as degradation of native leptin became more pronounced the greater stability of the leptin conjugates became more evident. In addition, Lep(ss)-P85(H) brain samples collected from mice with a brain washout were also more stable than that of Lep(ss)-P85(L) and leptin (51\% vs 34\% and 17\%).

3.3.4. Brain uptake-The brain uptake (\%inj/g brain) was determined at $240 \mathrm{~min}$ following i.v. administration of ${ }^{125} \mathrm{I}-\mathrm{Lep}(\mathrm{ss})-\mathrm{P} 85(\mathrm{H})$ or ${ }^{125} \mathrm{I}$-Lep(ss)-P85(L) with coinjection of ${ }^{131} \mathrm{I}$-leptin. To obtain the uptake of intact protein in the brain parenchyma, the $\%$ inj/g in brain was corrected for the Vi of each radioactively labeled substance. The resulting brain uptake of Lep(ss)-P85(L) and Lep(ss)-P85(H) more likely represents the amount of the substance that has crossed the BBB and as presented here shows that both compounds had significantly higher brain uptakes compared to that of native leptin (Fig. 9).

3.3.5. Inhibition study-The role of the leptin transporter in the BBB penetration of the leptin analogs was assessed by the effect of co-injection of excess of nonradio-active leptin $\left(10 \mu \mathrm{g} /\right.$ mouse) on the brain uptake of ${ }^{125}$ I labeled leptin- $P 85$ conjugates and coinjected ${ }^{131}$ I-leptin at 30 min following injection. As shown in Fig. 10, in the presence of free leptin, both ${ }^{125} \mathrm{I}$-Lep(ss)- P85(L) and ${ }^{131} \mathrm{I}$-leptin showed a significant decrease in their brain/ serum ratios ( $p<0.05$ for ${ }^{125}$ I-Lep(ss)-P85(L) and $p<0.005$ for ${ }^{131}$ I-leptin, $n=10$ / group), whereas no significant changes was observed for ${ }^{125} \mathrm{I}-\mathrm{Lep}(\mathrm{ss})-\mathrm{P} 85(\mathrm{H})(n=10$ / group). These results suggest that leptin modified by a single P85 chain crosses the BBB using leptin transporter; however, Lep(ss)-P85(H) modified with several P85 chains enters the brain independently of the leptin transporter.

\section{Discussion}

Modification of proteins with synthetic polymers has been studied for several decades. PEGylation, the leading technology in this field, has achieved enormous success in improving bioavailability and therapeutic efficacy of proteins for diseases with peripheral pathological targets. Like PEGylation, modifications with amphiphilic Pluronic triblock copolymers can decrease degradation of proteins in physiological fluids. Additionally, it increases permeability of proteins at physiological barriers, such as the BBB. Leptin, is one of the molecules that we have modified using this technology, aiming to improve its brain 
delivery and effects on feeding. The first generation of leptin-P85 conjugate, Lep(ss)-P85 was biologically active and reduced food intake of normal body weight mice at doses of 3 $\mathrm{mg} / \mathrm{mouse}$ i.v. and $25 \mu \mathrm{g} / \mathrm{mouse}$ i.c.v. [29]. An extensive PK study reported for Lep(ss)-P85 showed its longer blood circulation, better stability in serum and brain, and most importantly, transport across the BBB via a leptin transporter independent pathway [29]. This suggests that pluronic modification can potentially overcome leptin peripheral resistance and formed the basis for the further work reported here.

The initial progress in this work was the improvement of the purification of Lep(ss)-P85 by SEC, allowing the removal of the majority of unmodified leptin and isolation of two more homogenous conjugates: Lep(ss)-P85(L) and Lep(ss)-P85(H). Next, we studied serum and brain PK for these two conjugates and compared them to the native leptin. We found that 1) both conjugates were superior to the native leptin in terms of the blood PK and 2) the higher the modification degree of the conjugate is, the greater their blood half-life and serum stability are (i.e. Lep(ss)-P85(H) N Lep(ss)-P85(L) N leptin). Moreover, in the brain tissue Lep(ss)-P85(H) was also more stable than Lep(ss)-P85(L) and both conjugates were much more stable than native leptin. Notably, both Lep(ss)-P85(H) and Lep(ss)-P85(L) entered the brain from the blood at slower rates than that of leptin. However, despite their decreased influx rate, both Lep(ss)-P85(L) and Lep(ss)-P85(H) accumulated in the brain in greater amounts than leptin as assessed at $240 \mathrm{~min}$ after injection. The increased uptake of these conjugates to the brain is most likely due to the improvement in their peripheral PK and the higher stability within the brain, which compensate for some loss of their BBB permeability.

Remarkably, the transport inhibition studies demonstrated that these conjugates exploited strikingly different pathways for the brain entry. Specifically, Lep(ss)-P85(H) was crossing the BBB by a mechanism independent of the leptin transporter; whereas Lep(ss)-P85(L) penetrated the BBB by a mechanism inhibited by leptin. We posit that attaching multiple P85 chains to leptin in Lep(ss)-P85(H), could considerably diminish its interaction with the leptin transporter at the BBB. However, hydrophobic PPG blocks could interact with lipids membranes and as a synthetic carrier, triggering the endocytosis of Lep(ss)-P85(H) at the brain endothelium. P85 alone, for example, is known to bind to lipid rafts and transport in brain microvessel endothelial cells through both caveolae and caveolae- and clathrinindependent endocytosis routes [51,52]. It is possible that similar mechanisms are also involved in the BBB permeability of Lep(ss)-P85(H) in vivo with P85 chains attached to leptin serving as synthetic transport elements. Lipid moieties have been purposefully introduced to therapeutic small molecules and peptides to gain a better penetration at the BBB via diffusion mechanism [53]. However, to date, the largest reported molecule to diffuse across the BBB is CICN1 with molecular weight of $7.8 \mathrm{kDa}$, at least 4 time smaller than Lep(ss)-P85(H) (N26 kDa) [54]. Therefore it is less likely that the slow and nonsaturable penetration of Lep(ss)-P85(H) involves trans-cellular diffusion at the brain endothelium. In a striking difference Lep(ss)-P85(L) modified with a single copolymer chain seems to cross the BBB mainly via interaction with the leptin transporter. This suggests that on the one hand attaching a single P85 chain to leptin possibly cannot trigger sufficient hydrophobic interaction with brain endothelium necessary to bypass the BBB 
transporter. On the other hand, modification of leptin with a single P85 chain does not completely block the ability of the analog to bind the leptin transporter.

In parallel to the purification and brain PK profile, we characterized the physicochemical properties of leptin-P85 conjugates by various analytical assays. Using Lep(ss)-P85 as an example, we observed an increase in the hydrodynamic diameter of particles measured by DLS, suggesting some aggregation of the modified protein that may be an issue for further pharmaceutical development. We also observed some changes in the secondary structure of the modified leptin analog, which was not rectified by chemical cleavage of the P85 chains in a test tube. Interestingly, the binding affinity of Lep(ss)-P85 to its receptor in SPR assay was 500 fold less than that of leptin, whereas in the cell proliferation assay it was only 5 fold less as compared to leptin. The apparent discrepancy is not very clear and may have something to do with differences in interaction of P85 modified protein with SPR substrate and cell membranes. In the first case the block copolymer chains may adhere to and mask the leptin sites responsible for binding with the receptor. This may also involve unconjugated leptin molecules, which could incorporate into protein aggregates observed by the DLS. In the proliferation assay studies, however, the block copolymer chains may bind with the cell membrane thus making leptin molecules more available for interacting with their receptors. This speculation of course would need to be confirmed in the future.

We also for the first time report here the points of the copolymer attachment to leptin in the Lep(ss)-P85 conjugates as determined by Orbitrap mass spectrometry. These are amino groups of Lys 6, 12, 16, 34 and 107. To visualize how each modification could affect leptin interaction with its receptor, we determined the 3D structure of each isomer of P85 modified leptin using molecular modeling and further aligned the structure with a reported molecular model of putative leptin-receptor complex [55]. Attaching P85 at Lys 6 and 12 notably causes steric hindrance for leptin interaction with its receptor. However, modification at Lys 16, 34, 107 in all likelihood provides less steric barrier for the leptin-receptor binding (Supplementary data Fig. S6). Notably, the leptin transporter at the BBB displays structural similarity to the leptin receptor [56]. Therefore, the results of this analysis may explain why Lep(ss)-P85(L) modified with a single copolymer chain is still capable to transport across the BBB via the receptor mediated route. However, the leptin analog with higher modification degree, Lep(ss)-P85(H) seems to be less likely to enter the brain though the transporter dependent pathway. However, these two analogs did not show much difference in cell proliferation assay, which complicates the simple explanation and may mean that the binding of these analogs with receptors in cell membranes is more complex than assumed in the model.

In the design of our leptin-pluronic conjugates, we purposefully introduced the disulfide bond, the linkage that can degrade intracellularly yet is relatively stable in plasma [34]. With this reversible disulfide bond, Lep(ss)-P85 might act as a prodrug that presents in a modified form during circulation, allowing for improved peripheral bioavailability, but then releases free leptin with translocation across the BBB. Indeed, we found no disulfide breakdown upon exposure of Lep(ss)-P85 to serum for up to $24 \mathrm{hr}$. Our most recent results also suggest that the conjugates are fairly stable after exposure to brain homogenates. Whether the conjugate is broken down during penetration of the BBB is yet to be 
determined. On the other hand Lep(ss)-P85 conjugate was shown to release leptin, albeit incompletely, when treated with L-glutathione, an agent, which at least partially recaptures the reductive intracellular environment. This suggests the possibility that leptin might be released from its prodrug Lep(ss)-P85 within brain endothelium.

Finally we tested the anti-obese effect of leptin-P85 conjugates in two models of obese mice. The ideal and most interesting compound in this regard would be Lep(ss)-P85(H), considering its lower heterogeneity, improved PK profile, and BBB penetration independent of the leptin transporter. However the current conjugation chemistry and post purification procedure limit the supply of a large quantity of Lep(ss)-P85(H) for feeding studies. As we think the rationale of modification is to overcome peripheral resistance, which was shown by both Lep(ss)-P85(H) and Lep(ss)-P85, the latter compound, which at this stage is easier and more affordable to produce in needed amounts, was tested here. The first model was the ob/ob mouse that produces no leptin and is very sensitive to its effects. It was used here to determine whether the conjugated leptin retained any biological activity. We found that a rather modest dose of $40 \mu \mathrm{g} /$ mouse given by the s.c. route decreased both feeding and body weight. This showed that the mixture form of leptin-pluronic conjugate, Lep(ss)-P85 can be produced that retains leptin-like activity. It is very likely that all three components of Lep(ss)-P85, Lep(ss)- P85(L), Lep(ss)-P85(H) and native leptin can contribute to this activity because each component can be transported across the BBB of ob/ob mice. The second model we tested was the DIO mouse, which demonstrates both central and especially peripheral resistance to leptin. We found that Lep(ss)-P85 was active after i.c.v. injection, demonstrating its activity once it reaches leptin receptors at the arcuate nucleus. We then determined whether i.v. injected Lep(ss)-P85 could inhibit feeding. This would require leptin to cross the BBB in the animal model that is characterized by peripheral resistance to leptin. We found that tail vein injection evoked an acute response in reduction of food intake at a dose of $3 \mathrm{mg} / \mathrm{mouse}$. In contrast to ob/ob mice, DIO mice most likely cannot respond to Lep(ss)- P85(L) and native leptin forms because of insufficient transport of these forms to the brain. At the same time, Lep(ss)-P85(H) penetrates to the brain and thus contributes to the food reduction effect observed in DIO mice. While the ultimate goal is to prove its improvement in treating DIO, we are currently exploring the dose response curve of leptin substance and hope to address this key question based on an appropriate dose comparison between leptin and the conjugates in either acute or/and long term feeding experiment.

\section{Conclusion}

In this study we generated two new leptin-pluronic conjugates. Lep(ss)-P85(H), a leptin analog containing multiple P85 chains and Lep(ss)-P85(L), a leptin analog containing one P85 chain. Lep(ss)- P85(H) is a promising anti-obesity drug candidate because of its improvement in peripheral bioavailability, its increased brain uptake and, most importantly, its ability to cross the BBB independently of the leptin transporter. Lep(ss)-P85(L) also shows promise to be developed as leptin therapy alternative because of improved PK and brain bioavailability. 


\section{Supplementary Material}

Refer to Web version on PubMed Central for supplementary material.

\section{Acknowledgments}

This study was supported by the grants of the National Institutes of Health RO1 NS051334 and Center for Biomedical Research Excellence (CoBRE) Nebraska Center for Nanomedicine. We gratefully acknowledge the UNMC Mass Spectrometry and Proteomics Core Facility for assistance in MALDI-TOF and N-terminal sequencing experiments and UNMC Molecular Interaction Core Facility for assistance in SPR studies. The LC-MS experiment is based in part upon work conducted using the UNC Michael Hooker Proteomics Center, which is supported in part by the NIH-NCI Grant No. CA016086 to the UNC Lineberger Comprehensive Cancer Center. We were also grateful to Dr. Steve Roffler from the Institute of Biomedical Sciences, Academia Sinica, Taibei, Taiwan for helping with immunoassay using Anti-PEG antibody.

\section{References}

1. Ahima RS, Prabakaran D, Mantzoros C, Qu D, Lowell B, Maratos-Flier E, Flier JS. Role of leptin in the neuroendocrine response to fasting. Nature. 1996; 382:250-252. [PubMed: 8717038]

2. Friedman JM, Halaas JL. Leptin and the regulation of body weight in mammals. Nature. 1998; 395:763-770. [PubMed: 9796811]

3. Zhang Y, Proenca R, Maffei M, Barone M, Leopold L, Friedman JM. Positional cloning of the mouse obese gene and its human homologue. Nature. 1994; 372:425-432. [PubMed: 7984236]

4. Banks WA, Kastin AJ, Huang W, Jaspan JB, Maness LM. Leptin enters the brain by a saturable system independent of insulin. Peptides. 1996; 17:305-311. [PubMed: 8801538]

5. Wu-Peng XS, Chua SC Jr. Okada N, Liu SM, Nicolson M, Leibel RL. Phenotype of the obese Koletsky (f) rat due to Tyr763Stop mutation in the extracellular domain of the leptin receptor (Lepr): evidence for deficient plasma-to-CSF transport of leptin in both the Zucker and Koletsky obese rat. Diabetes. 1997; 46:513-518. [PubMed: 9032111]

6. Schwartz MW, Woods SC, Porte D Jr. Seeley RJ, Baskin DG. Central nervous system control of food intake. Nature. 2000; 404:661-671. [PubMed: 10766253]

7. Levin BE, Dunn-Meynell AA, Banks WA. Obesity-prone rats have normal blood-brain barrier transport but defective central leptin signaling before obesity onset. Am. J. Physiol. 2004; 286:R143-R150.

8. Roth JD, Roland BL, Cole RL, Trevaskis JL, Weyer C, Koda JE, Anderson CM, Parkes DG, Baron AD. Leptin responsiveness restored by amylin agonism in diet-induced obesity: evidence from nonclinical and clinical studies. Proc. Natl. Acad. Sci. U. S. A. 2008; 105:7257-7262. [PubMed: 18458326]

9. Ravussin E, Smith SR, Mitchell JA, Shringarpure R, Shan K, Maier H, Koda JE, Weyer C. Enhanced weight loss with pramlintide/metreleptin: an integrated neurohormonal approach to obesity pharmacotherapy. Obesity (Silver Spring). 2009; 17:1736-1743. [PubMed: 19521351]

10. Van Heek M, Compton DS, France CF, Tedesco RP, Fawzi AB, Graziano MP, Sybertz EJ, Strader CD, Davis HR Jr. Diet-induced obese mice develop peripheral, but not central, resistance to leptin. J. Clin. Invest. 1997; 99:385-390. [PubMed: 9022070]

11. Banks WA, Farrell CL. Impaired transport of leptin across the blood-brain barrier in obesity is acquired and reversible. Am. J. Physiol. Endocrinol. Metab. 2003; 285:E10-E15. [PubMed: 12618361]

12. Adam CL, Findlay PA. Decreased blood-brain leptin transfer in an ovine model of obesity and weight loss: resolving the cause of leptin resistance. Int. J. Obes. (Lond.). 2010; 34:980-988. [PubMed: 20142821]

13. Banks WA. Is obesity a disease of the blood-brain barrier? Physiological, pathological, and evolutionary considerations. Curr. Pharm. Des. 2003; 9:801-809. [PubMed: 12678879]

14. Halaas JL, Boozer C, Blair-West J, Fidahusein N, Denton DA, Friedman JM. Physiological response to long-term peripheral and central leptin infusion in lean and obese mice. Proc. Natl. Acad. Sci. U. S. A. 1997; 94:8878-8883. [PubMed: 9238071] 
15. LeBel C, Bourdeau A, Lau D, Hunt P. Biologic response to peripheral and central administration of recombinant human leptin in dogs. Obes. Res. 1999; 7:577-585. [PubMed: 10574517]

16. Heymsfield SB, Greenberg AS, Fujioka K, Dixon RM, Kushner R, Hunt T, Lubina JA, Patane J, Self B, Hunt P, McCamish M. Recombinant leptin for weight loss in obese and lean adults: a randomized, controlled, dose-escalation trial. JAMA. 1999; 282:1568-1575. [PubMed: 10546697]

17. Kahler A, Geary N, Eckel LA, Campfield LA, Smith FJ, Langhans W. Chronic administration of OB protein decreases food intake by selectively reducing meal size in male rats. Am. J. Physiol. 1998; 275:R180-R185. [PubMed: 9688977]

18. Hukshorn CJ, van Dielen FM, Buurman WA, Westerterp-Plantenga MS, Campfield LA, Saris WH. The effect of pegylated recombinant human leptin (PEGOB) on weight loss and inflammatory status in obese subjects. Int. J. Obes. Relat. Metab. Disord. 2002; 26:504-509. [PubMed: 12075577]

19. Lejeune MP, Hukshorn CJ, Saris WH, Westerterp-Plantenga MS. Effect of dietary restraint during and following pegylated recombinant leptin (PEG-OB) treatment of overweight men. Int. J. Obes. Relat. Metab. Disord. 2003; 27:1494-1499. [PubMed: 14634680]

20. Haun SE, Kirsch JR, Helfaer MA, Kubos KL, Traystman RJ. Polyethylene glycolconjugated superoxide dismutase fails to augment brain superoxide dismutase activity in piglets. Stroke. 1991; 22:655-659. [PubMed: 2028497]

21. Wu D, Pardridge WM. Neuroprotection with noninvasive neurotrophin delivery to the brain. Proc. Natl. Acad. Sci. U. S. A. 1999; 96:254-259. [PubMed: 9874805]

22. Pardridge WM, Wu D, Sakane T. Combined use of carboxyl-directed protein pegylation and vector-mediated blood-brain barrier drug delivery system optimizes brain uptake of brain-derived neurotrophic factor following intravenous administration. Pharm. Res. 1998; 15:576-582. [PubMed: 9587954]

23. Elinav E, Niv-Spector L, Katz M, Price TO, Ali M, Yacobovitz M, Solomon G, Reicher S, Lynch JL, Halpern Z, Banks WA, Gertler A. Pegylated leptin antagonist is a potent orexigenic agent: preparation and mechanism of activity. Endocrinology. 2009; 150:3083-3091. [PubMed: 19342450]

24. Lo KM, Zhang J, Sun Y, Morelli B, Lan Y, Lauder S, Brunkhorst B, Webster G, Hallakou-Bozec S, Doare L, Gillies SD. Engineering a pharmacologically superior form of leptin for the treatment of obesity. Protein Eng. Des. Sel. 2005; 18:1-10. [PubMed: 15790575]

25. Wu Y, Cain-Hom C, Choy L, Hagenbeek TJ, de Leon GP, Chen Y, Finkle D, Venook R, Wu X, Ridgway J, Schahin-Reed D, Dow GJ, Shelton A, Stawicki S, Watts RJ, Zhang J, Choy R, Howard P, Kadyk L, Yan M, Zha J, Callahan CA, Hymowitz SG, Siebel CW. Therapeutic antibody targeting of individual Notch receptors. Nature. 2010; 464:1052-1057. [PubMed: 20393564]

26. Herve F, Ghinea N, Scherrmann JM. CNS delivery via adsorptive transcytosis. AAPS J. 2008; 10:455-472. [PubMed: 18726697]

27. Kovalszky I, Surmacz E, Scolaro L, Cassone M, Ferla R, Sztodola A, Olah J, Hatfield MP, Lovas S, Otvos L Jr. Leptin-based glycopeptide induces weight loss and simultaneously restores fertility in animal models. Diabetes Obes. Metab. 2010; 12:393-402. [PubMed: 20415687]

28. Banks WA. Enhanced leptin transport across the blood-brain barrier by alpha 1-adrenergic agents. Brain Res. 2001; 899:209-217. [PubMed: 11311882]

29. Price TO, Farr SA, Yi X, Vinogradov S, Batrakova E, Banks WA, Kabanov AV. Transport across the blood-brain barrier of pluronic leptin. J. Pharm. Exp. Ther. 2010; 333:253-263.

30. Yi X, Batrakova E, Banks WA, Vinogradov S, Kabanov AV. Protein conjugation with amphiphilic block copolymers for enhanced cellular delivery. Bioconjug. Chem. 2008; 19:1071-1077. [PubMed: 18447367]

31. Whitmore L, Wallace BA. Protein secondary structure analyses from circular dichroism spectroscopy: methods and reference databases. Biopolymers. 2008; 89:392-400. [PubMed: 17896349]

32. Whitmore L, Wallace BA. DICHROWEB, an online server for protein secondary structure analyses from circular dichroism spectroscopic data. Nucleic Acids Res. 2004; 32:W668-W673. [PubMed: 15215473] 
33. Wisniewski JR, Zougman A, Nagaraj N, Mann M. Universal sample preparation method for proteome analysis. Nat. Methods. 2009; 6:359-362. [PubMed: 19377485]

34. Saito G, Swanson JA, Lee KD. Drug delivery strategy utilizing conjugation via reversible disulfide linkages: role and site of cellular reducing activities. Adv. Drug Deliv. Rev. 2003; 55:199-215. [PubMed: 12564977]

35. Cuchelkar V, Kopeckova P, Kopecek J. Synthesis and biological evaluation of disulfide-linked HPMA copolymer-mesochlorin e6 conjugates. Macromol. Biosci. 2008; 8:375-383. [PubMed: 18215003]

36. Wright JE, Gittens SA, Bansal G, Kitov PI, Sindrey D, Kucharski C, Uludag H. A comparison of mineral affinity of bisphosphonate-protein conjugates constructed with disulfide and thioether linkages. Biomaterials. 2006; 27:769-784. [PubMed: 16055182]

37. Mistrik P, Moreau F, Allen JM. BiaCore analysis of leptin-leptin receptor interaction: evidence for 1:1 stoichiometry. Anal. Biochem. 2004; 327:271-277. [PubMed: 15051545]

38. Morley JE, Alshaher MM, Farr SA, Flood JF, Kumar VB. Leptin and neuropeptide Y (NPY) modulate nitric oxide synthase: further evidence for a role of nitric oxide in feeding. Peptides. 1999; 20:595-600. [PubMed: 10465511]

39. Patlak CS, Blasberg RG, Fenstermacher JD. Graphical evaluation of blood-to-brain transfer constants from multiple-time uptake data. J. Cereb. Blood Flow Metab. 1983; 3:1-7. [PubMed: 6822610]

40. Blasberg RG, Fenstermacher JD, Patlak CS. Transport of alpha-aminoisobutyric acid across brain capillary and cellular membranes. J. Cereb. Blood Flow Metab. 1983; 3:8-32. [PubMed: 6822623]

41. Yi X, Zimmerman MC, Yang R, Tong J, Vinogradov S, Kabanov AV. Pluronicmodified superoxide dismutase 1 attenuates angiotensin II-induced increase in intracellular superoxide in neurons. Free Radic. Biol. Med. 2010; 49:548-558. [PubMed: 20493251]

42. Snider J, Neville C, Yuan LC, Bullock J. Characterization of the heterogeneity of polyethylene glycol-modified superoxide dismutase by chromatographic and electrophoretic techniques. J. Chromatogr. 1992; 599:141-155. [PubMed: 1618987]

43. Salomon G, Niv-Spector L, Gussakovsky EE, Gertler A. Large-scale preparation of biologically active mouse and rat leptins and their L39A/D40A/F41A muteins which act as potent antagonists. Protein Expr. Purif. 2006; 47:128-136. [PubMed: 16289983]

44. Cheng TL, Chen BM, Chan LY, Wu PY, Chern JW, Roffler SR. Poly(ethylene glycol) modification of beta-glucuronidase-antibody conjugates for solid-tumor therapy by targeted activation of glucuronide prodrugs. Cancer Immunol. Immunother. 1997; 44:305-315. [PubMed: 9298932]

45. Cheng TL, Cheng CM, Chen BM, Tsao DA, Chuang KH, Hsiao SW, Lin YH, Roffler SR. Monoclonal antibody-based quantitation of poly(ethylene glycol)-derivatized proteins, liposomes, and nanoparticles. Bioconjug. Chem. 2005; 16:1225-1231. [PubMed: 16173802]

46. Cheng TL, Wu PY, Wu MF, Chern JW, Roffler SR. Accelerated clearance of polyethylene glycolmodified proteins by anti-polyethylene glycol IgM. Bioconjug. Chem. 1999; 10:520-528. [PubMed: 10346886]

47. Chuang KH, Tzou SC, Cheng TC, Kao CH, Tseng WL, Shiea J, Liao KW, Wang YM, Chang YC, Huang BJ, Wu CJ, Chu PY, Roffler SR, Cheng TL. Measurement of poly(ethylene glycol) by cellbased anti-poly(ethylene glycol) ELISA. Anal. Chem. 2010; 82:2355-2362. [PubMed: 20178318]

48. Hanada T, Noda NN, Satomi Y, Ichimura Y, Fujioka Y, Takao T, Inagaki F, Ohsumi Y. The Atg12-Atg5 conjugate has a novel E3-like activity for protein lipidation in autophagy. J. Biol. Chem. 2007; 282:37298-37302. [PubMed: 17986448]

49. Tsai NM, Cheng TL, Roffler SR. Sensitive measurement of polyethylene glycolmodified proteins. BioTechniques. 2001; 30:396-402. [PubMed: 11233609]

50. Banks WA, McLay RN, Kastin AJ, Sarmiento U, Scully S. Passage of leptin across the bloodtestis barrier. Am. J. Physiol. 1999; 276:E1099-E1104. [PubMed: 10362623]

51. Sahay G, Alakhova DY, Kabanov AV. Endocytosis of nanomedicines. J. Control. Release. 2010; 145:182-195. [PubMed: 20226220] 
52. Sahay G, Gautam V, Luxenhofer R, Kabanov AV. The utilization of pathogen-like cellular trafficking by single chain block copolymer. Biomaterials. 2010; 31:1757-1764. [PubMed: 19963266]

53. Witt KA, Gillespie TJ, Huber JD, Egleton RD, Davis TP. Peptide drug modifications to enhance bioavailability and blood-brain barrier permeability. Peptides. 2001; 22:2329-2343. [PubMed: 11786210]

54. Pan W, Kastin AJ. Changing the chemokine gradient: CINC1 crosses the blood-brain barrier. J. Neuroimmunol. 2001; 115:64-70. [PubMed: 11282155]

55. Carpenter B, Hemsworth GR, Wu Z, Maamra M, Strasburger CJ, Ross RJ, Artymiuk PJ. Structure of the human obesity receptor leptin-binding domain reveals the mechanism of leptin antagonism by a monoclonal antibody. Structure. 2012; 20:487-497. [PubMed: 22405007]

56. Hsuchou H, Kastin AJ, Tu H, Markadakis EN, Stone KP, Wang Y, Heymsfield SB, Chua SS Jr. Obici S, Magrisso IJ, Pan W. Effects of cell-type specific leptin receptor mutation on leptin transport across the BBB. Peptides. 2011; 32:1392-1399. [PubMed: 21616110] 


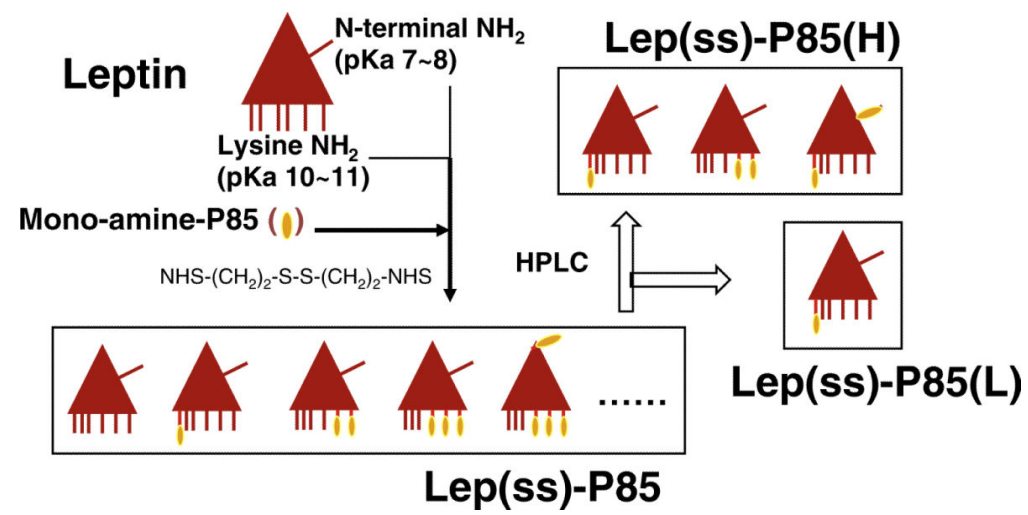

Scheme 1.

Generation of leptin-P85 conjugates by modifying leptin lysine and N-terminal amino groups with monoamine P85 via disulfide-containing linker. The leptin-P85 conjugate Lep(ss)-P85 was further purified to produce Lep(ss)-P85(L) and Lep(ss)-P85(H). 

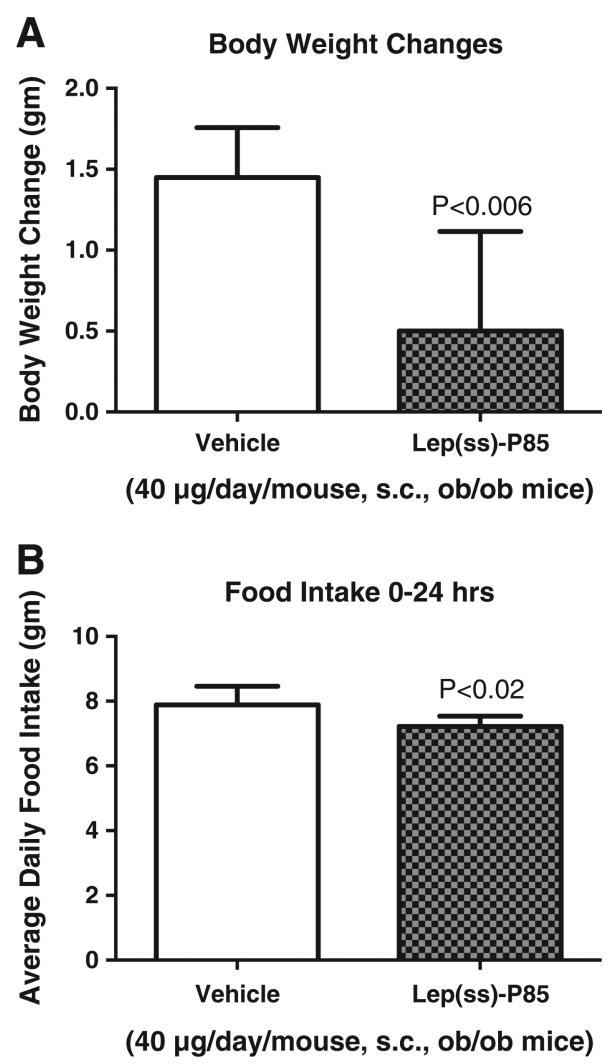

Fig. 1.

The effect of peripherally administered Lep(ss)-P85 in ob/ob mouse. (A) Body weight in ob/ob mice after 3 days of Lep(ss)-P85 treatment (40 $\mu$ g/day/mouse, s.c.) was significantly decreased ( $p<0.006$, by $t$-test). (B) Lep(ss)-P85 treatment also induced a significant reduction in average daily food intake ( $p<0.02$, by $t$-test $)(n=6$ for vehicle group and $n=7$ for Lep(ss)-P85 group). 

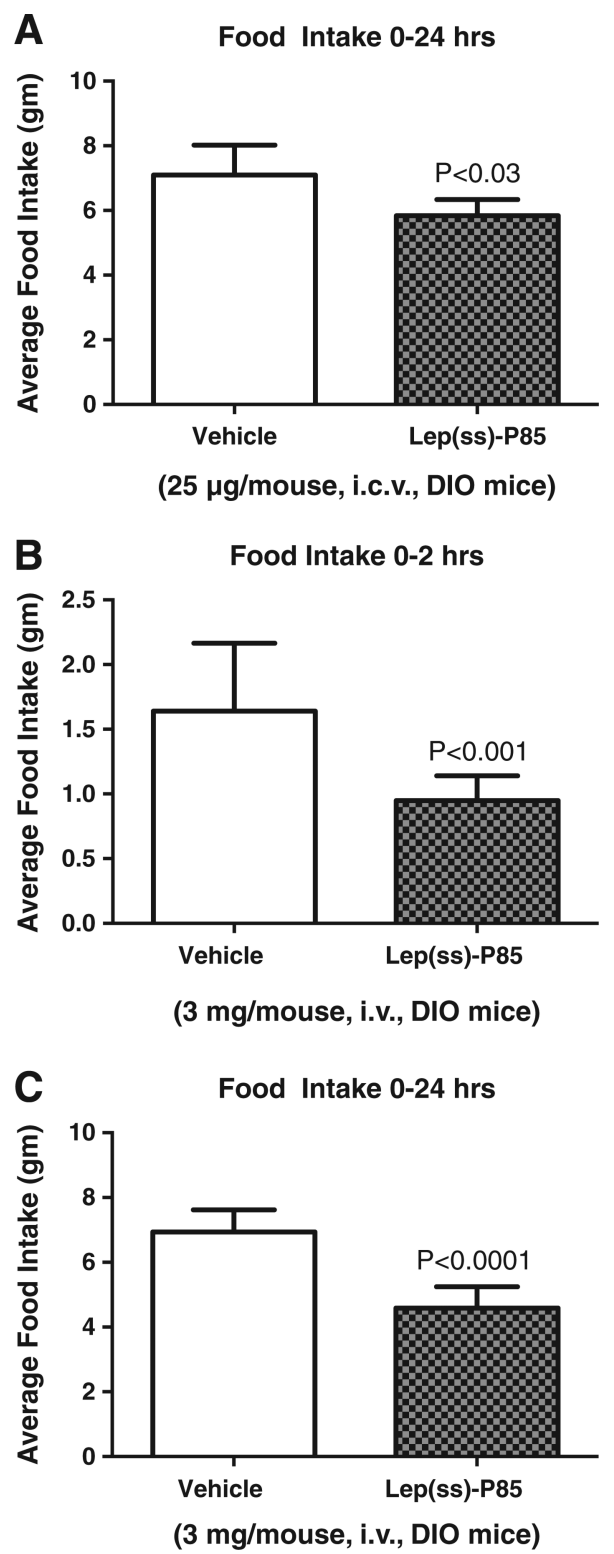

Fig. 2.

The effects of Lep(ss)-P85 in DIO mice. (A) The DIO mice that received $25 \mu \mathrm{g} / \mathrm{mouse}$ i.c.v. Lep(ss)-P85 ate significantly less food $24 \mathrm{hr}$ post food induction than mice that was given with vehicle. ( $n=5 /$ group, $p<0.03$, by $t$-test). (B and C) Tail vein injection of Lep(ss)-P85 at a dose of $3 \mathrm{mg}$ per mouse significantly reduced food intake of DIO mice $2 \mathrm{hr}(p<0.001)$ and $24 \mathrm{hr}(p<0.0001)$ post food induction ( $n=10$ /group). 

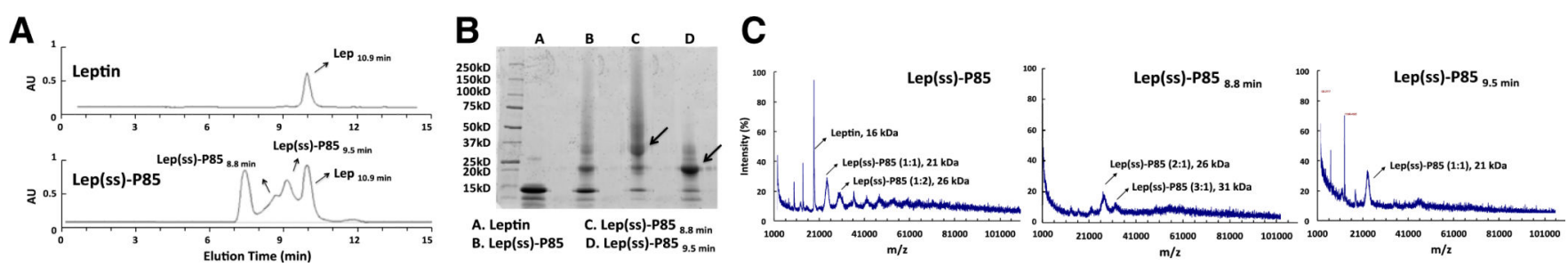

Fig. 3.

Purification and characterization of leptin-P85 conjugates. (A) Lep(ss)-P85 conjugate contained unmodified leptin and leptin modified with different numbers of P85 chains. SEC elution profile in TSKgel G2000SW column showed separation of leptin-P85 conjugates from unmodified leptin. (B) SDS-PAGE and (C) MALDI-TOF spectra further characterized the collected fractions at $8.8 \mathrm{~min}$ and $9.5 \mathrm{~min}$ as leptin conjugates modified with multiple P85 chains (Lep(ss)-P85(H)) and single P85 chain (Lep(ss)-P85(L)), respectively. 

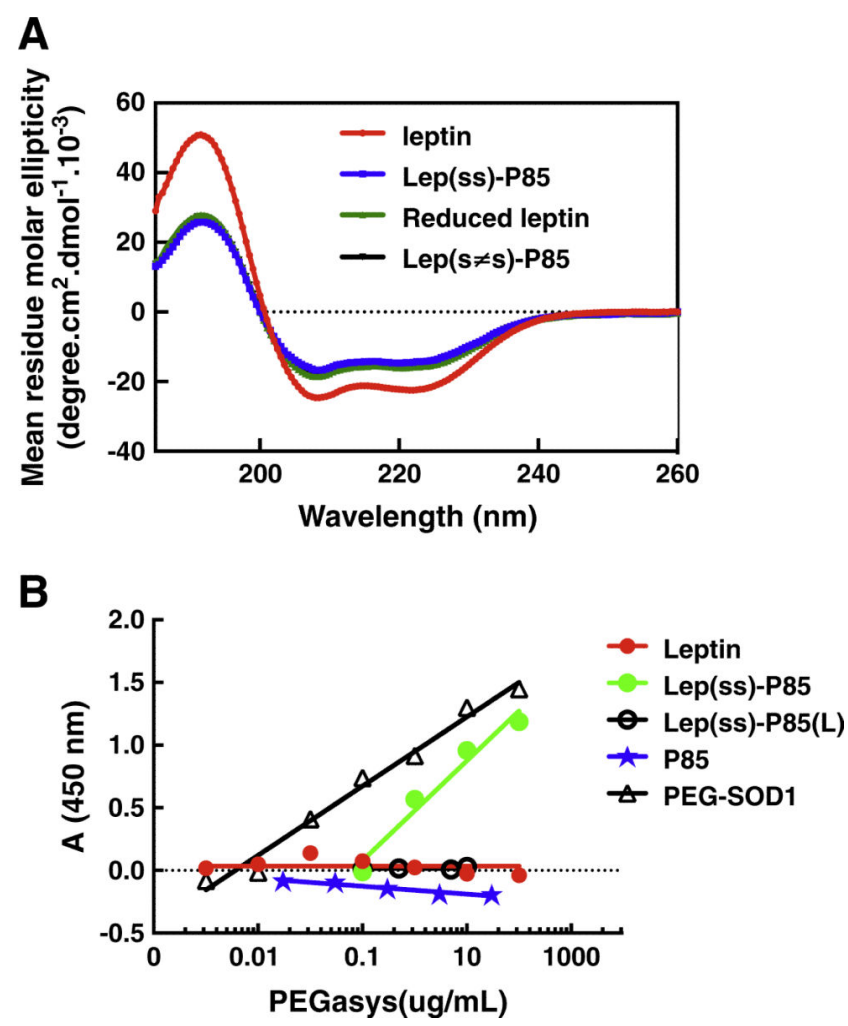

Fig. 4.

(A) CD spectra of native leptin and Lep(ss)-P85 before and after reduction of disul-fide

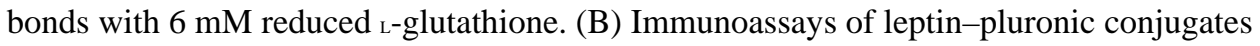
using antibody against PEG. Concentration-dependent ELISA signal was present in Lep(ss)P85, but not in free P85, native leptin or Lep(ss)-P85(L). A PEGylated protein (PEG-SOD1) was also assayed as a positive control showing that AGP 4 and 3.3-biotin antibody were able to recognize PEG containing species. 

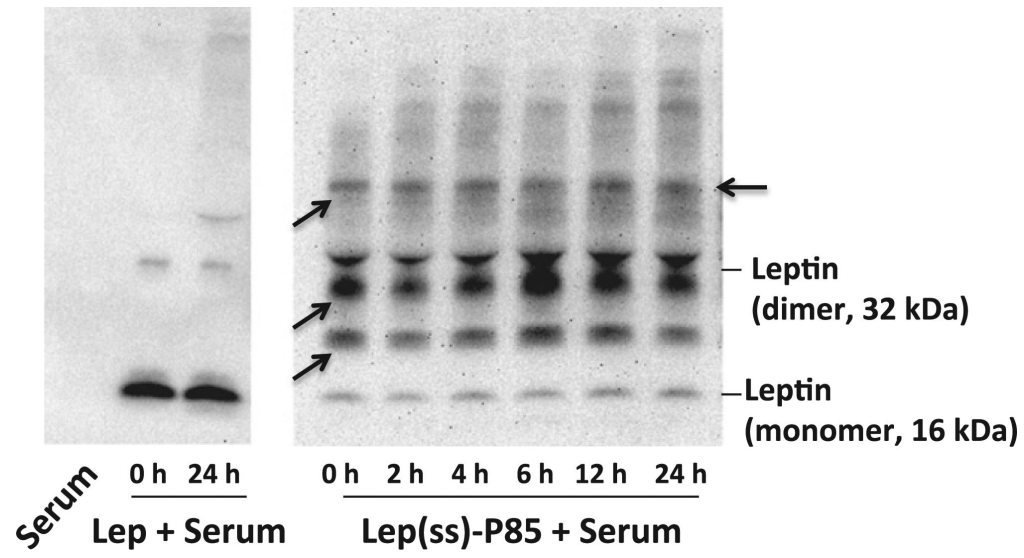

$\begin{array}{llllll}0 h & 2 h & 4 h \quad 6 h & 12 h \quad 24 h\end{array}$

Lep(ss)-P85 + Serum

Fig. 5.

Disulfide bond stability in Lep(ss)-P85 conjugate upon its exposure to serum. Western blot analysis shows that leptin or Lep(ss)-P85 remained stable after incubating with serum for up to $24 \mathrm{hr}$. 

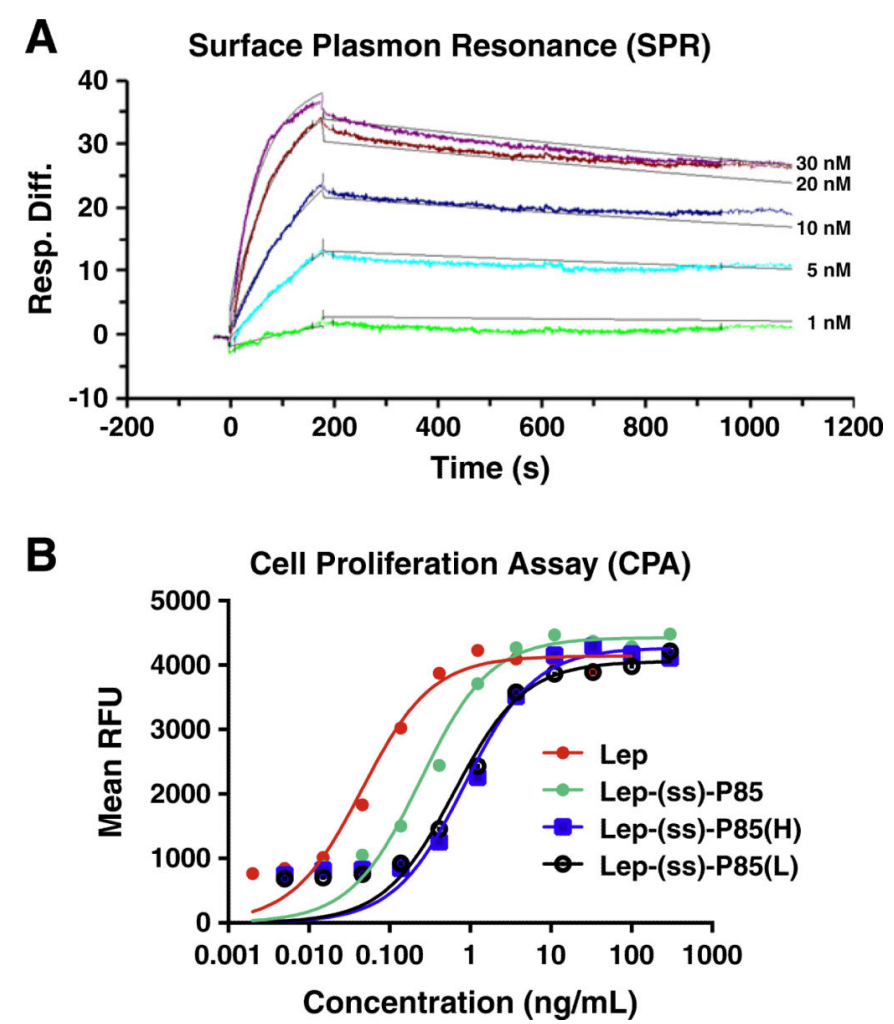

Fig. 6.

(A) Representative association and dissociation SPR sensorgrams of leptin-pluronic conjugate at various concentrations flowing on the sensor chip coupled by leptin receptor. (B) Binding curves of leptin-pluronic conjugates with BaF3 mouse pro-B cells transfected with human leptin receptor. 

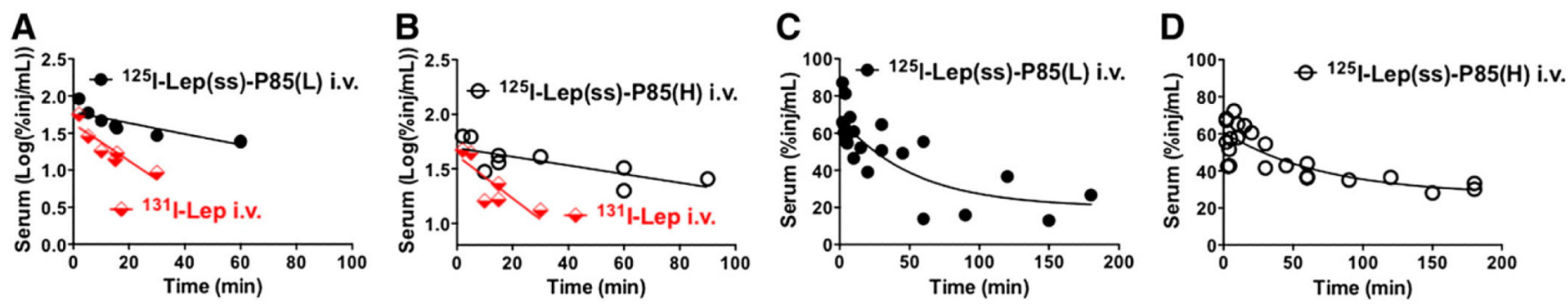

Fig. 7.

Serum clearance of leptin-pluronic conjugates during shorter (A and B) and longer time periods of study ( $\mathrm{C}$ and $\mathrm{D})$. The two lines in panels $\mathrm{A}$ and $\mathrm{B}$ were significantly different $(p<$ 0.05). Both ${ }^{125}$ I-Lep(ss)-P85(L) and ${ }^{125}$ I-Lep(ss)-P85(H) showed significantly longer circulation time than that of co-injected ${ }^{131} \mathrm{I}$-leptin. The serum disappearance $\left(T_{1 / 2}\right)$ was 40.75 min for ${ }^{125} \mathrm{I}-\mathrm{Lep}(\mathrm{ss})-\mathrm{P} 85(\mathrm{~L})(r=0.75, p<0.001 ; n=1 \sim 2$ mice/time point $), 75.80$ min for ${ }^{125} \mathrm{I}$-Lep(ss)-P85(H) $(r=0.73, p<0.0005 ; n=1 \sim 2$ mice/time point $)$ and $11.98 \mathrm{~min}$ for ${ }^{131}$ I-Lep ( $r=0.64, \mathrm{p} p<0.005 ; n=1 \sim 2$ mice/time point). The vascular volume distribution (Vi), as shown by the y intercept was not significantly different. Panels C and D further showed that initial serum clearance was a linear distribution for both of leptin analogs followed by a plateau phase. 

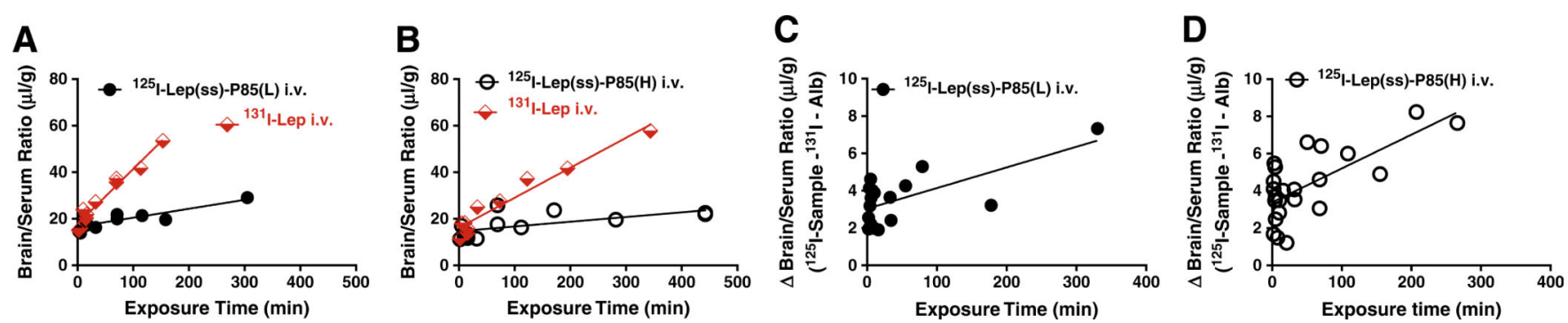

Fig. 8.

Multiple-time regression analysis of leptin-pluronic conjugate transport across the BBB. Leptin-P85 conjugates were labeled by ${ }^{125} \mathrm{I}$ and co-injected with ${ }^{131} \mathrm{I}$-lep (A and B) or ${ }^{131} \mathrm{IAlb}(\mathrm{C}$ and $\mathrm{D})$. (A and B) The two lines in each figure were statistically different ( $p<$ 0.0001). Both Lep(ss)-P85(L) and Lep(ss)-P85(H) showed a slower entry rate compared to that that of leptin. The brain volume distribution (Vi), however, was not significantly different. The Ki for Lep(ss)-P85(L) and Lep(ss)-P85(H) was $0.038 \pm 0.008 \mu \mathrm{L} / \mathrm{g} \cdot \min (r=$ $0.71, p<0.0 .005 ; n=1 \sim 2$ mice/time point $)$ and $0.020 \pm 0.007 \mu \mathrm{L} / \mathrm{g} \cdot \min (r=0.40, p<$ $0.05 ; n=1 \sim 2$ mice/time point), respectively. The Vi for Lep(ss)-P85(L) and Lep(ss)$\mathrm{P} 85(\mathrm{H})$ was $16.62 \pm 0.94 \mu \mathrm{L} / \mathrm{g}$ and $14.70 \pm 1.48 \mu \mathrm{L} / \mathrm{g}$, respectively. For native leptin coinjected with Lep(ss)-P85(L), the Ki was $0.236 \pm 0.017 \mu \mathrm{L} / \mathrm{g} \cdot \min$ and $\mathrm{Vi}$ was $17.17 \pm 1.19$ $\mu \mathrm{L} / \mathrm{g}(r=0.96, p<0.0001)$; for leptin co-injected with Lep(ss)-P85(H), the Ki was $0.129 \pm$ $0.011 \mu \mathrm{L} / \mathrm{g} \cdot \min$ and $\mathrm{Vi}$ was $16.16 \pm 1.49 \mu \mathrm{L} / \mathrm{g}(r=0.94, p<0.0001)$. Both leptin results were similar to those reported previously. (C and D) Results were corrected for vascular space as measured by ${ }^{131} \mathrm{I}$-Alb. Both leptin analogs showed residual uptake rates after this correction, suggesting that they had significantly higher entry rates than that of albumin. The Ki for Lep(ss)-P85(L) was $0.011 \pm 0.003 \mu \mathrm{L} / \mathrm{g} \cdot \mathrm{min}$; the Vi was $3.034 \pm 0.298 \mu \mathrm{L} / \mathrm{g}(r=$ $0.45, p<0.01 ; n=1 \sim 2$ mice/time point). The corrected Ki for Lep(ss)-P85(H) was $0.018 \pm$ $0.004 \mu \mathrm{L} / \mathrm{g} \cdot \min$; Vi was $3.391 \pm 0.35 \mu \mathrm{L} / \mathrm{g}(r=0.48, p<0.001 ; n=1 \sim 2$ mice/time point $)$. 


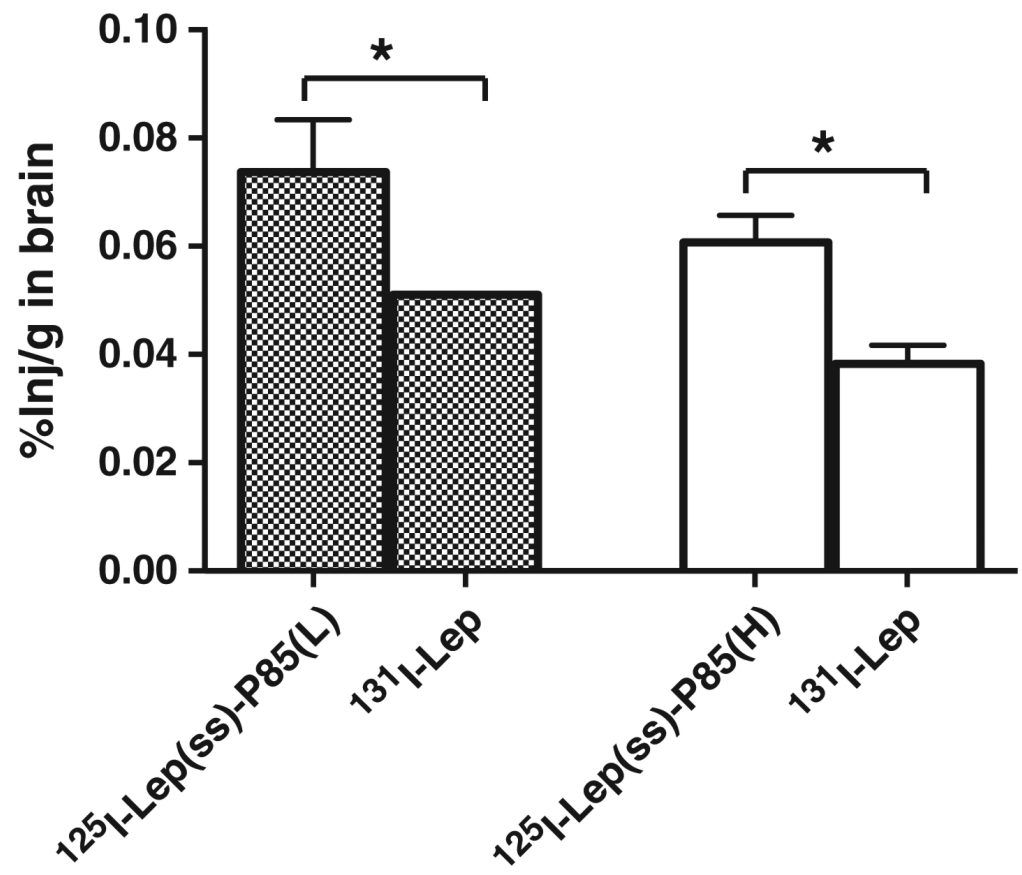

Fig. 9.

Brain uptake of intact leptin analogs at 240 min after i.v. injection. The brain uptake of ${ }^{125} \mathrm{I}-$ Lep(ss)-P85(L) or ${ }^{125}$ I-Lep(ss)-P85(H) was significantly higher than that of coinjected ${ }^{131}$ I-Lep ( $* p<0.05, n=2 \sim 3$ /group, by $t$-test). The brain uptake was expressed as $\%$ inj/g using Eq. (3) and then corrected for the stability of the brain samples (in washout brain) as assessed by TCA precipitation. 

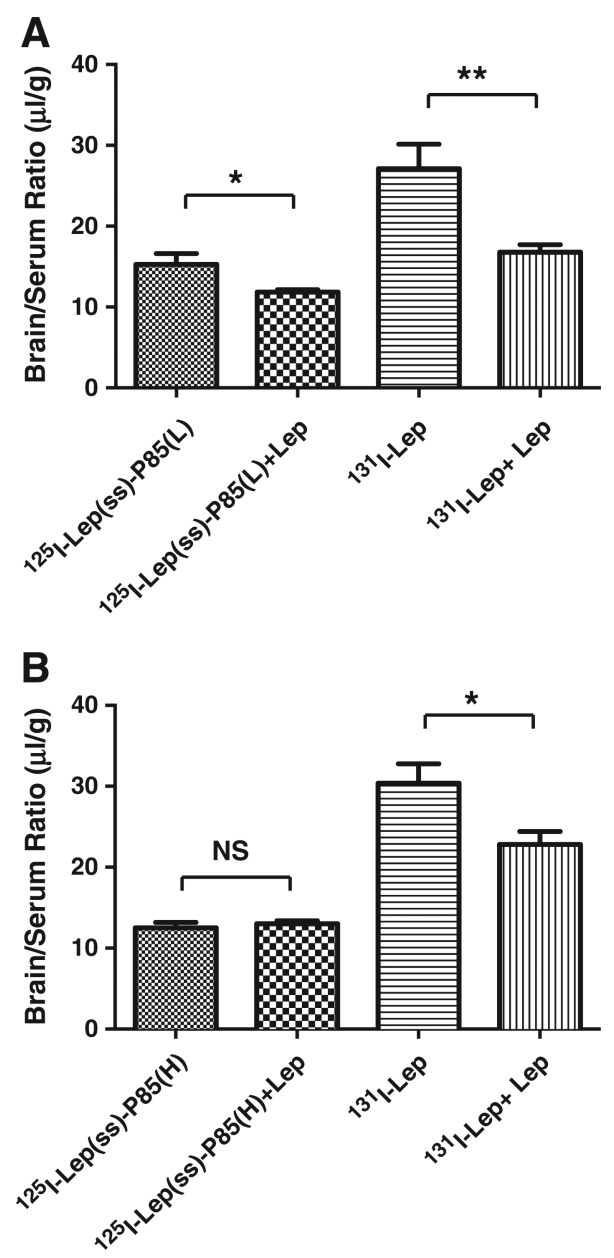

Fig. 10.

Transport mechanisms of leptin analogs. (A) Nonradioactive leptin (10 $\mu \mathrm{g} / \mathrm{mouse})$ inhibited the brain/serum ratio of both ${ }^{125} \mathrm{I}$-Lep(ss)-P85(L) and ${ }^{131}$ I-Lep at $30 \mathrm{~min}$ after intravenous injections $(* p<0.05 ; * *<0.001, n=10$ /group), suggesting a transporter dependent mechanism across the BBB. (B) The brain/serum ratio of ${ }^{125} \mathrm{I}-\mathrm{Lep}(\mathrm{ss})-\mathrm{P} 85(\mathrm{H})$ at $30 \mathrm{~min}$ after intravenous injections did not alter with or without excess of leptin $(10 \mu \mathrm{g} / \mathrm{mouse})\left({ }^{*} p\right.$ $<0.05, n=10$ /group). 


\section{Table 1}

Binding affinity and in vitro $\mathrm{IC}_{50}$ of leptin-pluronic conjugates.

\begin{tabular}{|c|c|c|c|c|}
\hline \multirow[t]{2}{*}{ Samples } & \multicolumn{2}{|c|}{$\underline{B i n d i n g ~ a f f i n i t y ~}^{a}$} & \multicolumn{2}{|c|}{ In vitro activity $b$} \\
\hline & $k_{\mathrm{D}}\left[10^{-10} \mathrm{M}\right]$ & $\chi^{2}$ & $\mathrm{IC}_{50}[\mathrm{ng} / \mathrm{mL}]$ & $R^{2}$ \\
\hline Leptin & $1.0 \pm 0.03$ & $0.1-0.4$ & 0.08 & 0.99 \\
\hline Leptin + P85 & $3.37 \pm 0.08$ & $0.3-0.5$ & ND & ND \\
\hline Lep(ss)-P85 & $571 \pm 91.50$ & $0.2-0.6$ & 0.448 & 0.99 \\
\hline Lep(s $\neq$ s)-P85 & $164 \pm 15.50$ & $0.2-0.3$ & ND & ND \\
\hline Lep(ss)-P85(H) & ND & ND & 1.472 & 0.99 \\
\hline Lep(ss)-P85(L) & $12.1 \pm 5.14$ & $0.8-1.5$ & 1.102 & 0.99 \\
\hline
\end{tabular}

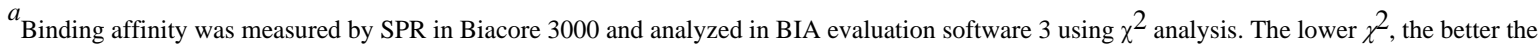
fitting is.

${ }^{b}$ IC50 was measured by CPA using BaF3 mouse pro-B cells transfected with human leptin receptor and calculated by four parameter fitting with $\mathrm{R}^{2}$ of 0.99 for all curves. 


\section{Table 2}

Acid precipitation of radioactively labeled leptin or its analogs in brain and serum.

\begin{tabular}{|c|c|c|c|c|c|c|}
\hline \multirow[t]{2}{*}{ Time (min) } & \multicolumn{2}{|l|}{ Leptin } & \multicolumn{2}{|c|}{ Lep(ss)-P85(L) } & \multicolumn{2}{|c|}{$\underline{\operatorname{Lep}(\mathrm{ss})-\operatorname{P85}(\mathrm{H})}$} \\
\hline & Serum $(\%)$ & Brain (\%) & Serum $(\%)$ & Brain (\%) & Serum $(\%)$ & Brain (\%) \\
\hline 15 & $94.4 \pm 3.6$ & $100.0 \pm 3.9$ & $104.0 \pm 0.7$ & $99.1 \pm 1.6$ & $100.3 \pm 6.5$ & $98.8 \pm 5.6$ \\
\hline 60 & $76.2 \pm 8.5$ & $73.0 \pm 13.7$ & $93.3 \pm 1.1$ & $73.9 \pm 1.6$ & $96.1 \pm 0.4$ & $81.9 \pm 0.4$ \\
\hline 240 & $52.8 \pm 8.7$ & $27.7 \pm 9.5$ & $71.0 \pm 2.7$ & $49.7 \pm 3.3$ & $86.0 \pm 3.4$ & $61.5 \pm 3.3$ \\
\hline $240^{a}$ & $35.7 \pm 10.9$ & $17.6 \pm 16.1$ & $74.0 \pm 1.1$ & $34.3 \pm 3.3$ & $87.0 \pm 1.01$ & $51.2 \pm 8.2$ \\
\hline
\end{tabular}

${ }^{a}$ Brain was collected in mice with a brain washout. 